جامعــة المنصـــــــة التربية

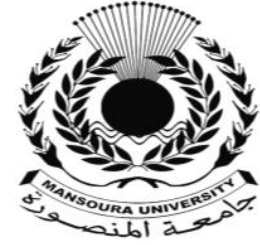

تصور مقترح قائم على الحوسبة السحابية لتطوير أداء هملهي المرحلة الثانوية بمحافظة الفروانية

\title{
بدولة الكويت
}

إعداد

د/ فهد العنزي

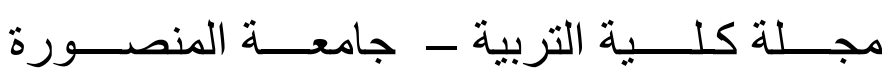

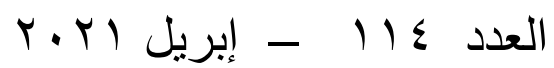




\section{تصور مقترح قائم على الحوسبة السحابية لتطوير أداء معلمي المرحلة الثانوية بمحافظة الفروانية بدولة الكويت الثرايت}

\section{د/ فهل العنزي}

$$
\begin{aligned}
& \text { ملخص الدر اسة } \\
& \text { هدفت الدراسة الى الكثف عن مدى وعى معلمى العرحلة الثانوية ببحافظة الفروانية بذولة الكويت } \\
& \text { باستخدام الحوسبة السحابية فى تطوير أدائهم ، مع تحديد المعوقات التى تقابلهم فى تطبيق الحوسبة } \\
& \text { السحابية وتقديم تصور مقترح لتفعيل الحوسبة السحابية فى العملية التعليية والتغلب على تلك المعوقات، }
\end{aligned}
$$

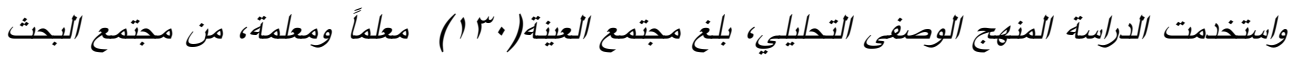

$$
\begin{aligned}
& \text { الاصلي، وقد قام بتوزيع الاستبانه على أفراد العينت وجدعها من المعلمين العاملين بدارس المرحلة الثانوية، } \\
& \text { وتوصلت الى أن نتائج الاستجابة لمعلمى المرحلة الثانوية حول مدى معرفتهم بتطبيقات الحوسبة السحابية } \\
& \text { بدرجة متوسطة من مهارات استخدام هذه التطبيقات يرجع ذلك الى خلفية المعلمين عن مهارات استخدام } \\
& \text { تطبيقات الحوسبة السحابية وان لليهم مستوى من المهارات يحتاج الى تنميته بطريقة تتناسب مع قدراتهم } \\
& \text { العملية، لذا من الضروري توعية المعلمين والطلبة حول أهمية استخدام الحوسبة السحابية في العملية } \\
& \text { التعليهة، ودورها في تحقيق العديد من الأهداف، ضرورة امتلاك المعلدين للمعارف والمهارات الكافية } \\
& \text { الستخدم الحاسوب في التدري،، أهدية تزويد الطلبة بعناوين الحسابات التي يمكنهم التواصل معها ومشاركة } \\
& \text { المستندات من خلالها، فقد اكدت نتائج استجابات عينة البحث على وجود معوقات لاستخد/م الحوسبة } \\
& \text { السحابية تحد من فاعليتها، ومن خلال النتائج تم وضع التصور المقترح. }
\end{aligned}
$$

\section{Abstract}

The study aimed to reveal the awareness of high school teachers in Farwaniya Governorate, Kuwait, about using cloud computing in developing their performance, while identifying the obstacles they encounter in applying cloud computing and presenting a proposed vision for activating cloud computing in the educational process and overcoming those obstacles, and the study used the descriptive and analytical approach, The sample community reached (130) male and female teachers from the original research community. The questionnaire was distributed among the sample members and collected from teachers working in secondary schools. It concluded that the results of the response for secondary school teachers about their knowledge of cloud computing applications with a moderate degree of skills in using these applications is due to the teachers 'background on the skills of using cloud computing applications and that they have 
a level of skills that needs to be developed in a manner commensurate with their practical capabilities, Therefore, it is necessary to educate teachers and students about the importance of using cloud computing in the educational process, and its role in achieving many goals, the need for teachers to possess sufficient knowledge and skills to use computers in teaching, the importance of providing students with account addresses that they can communicate with and share documents through, the results have been confirmed. The research sample responses to the presence of obstacles to the use of cloud computing that limit its effectiveness, and through the results the proposed scenario was developed.

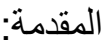

يثهد العالم اتساع الفجوات بين من فى متتاول ايديهم المعلومات والمعرفة، وبين من هم فى

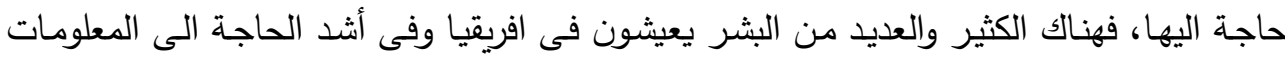

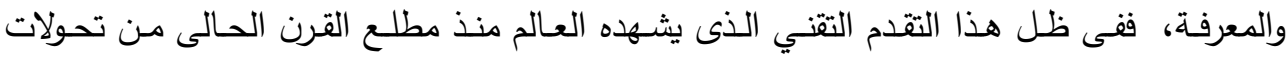

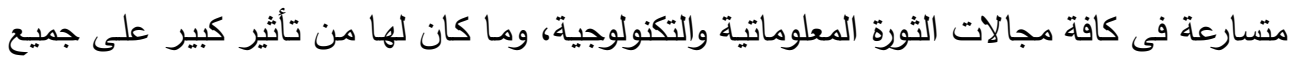
جوانب الحياة، ويتصدر الانترنت ذلك التطور، ويعتبر التعليم والتدريب من أهم مقومات المحاور

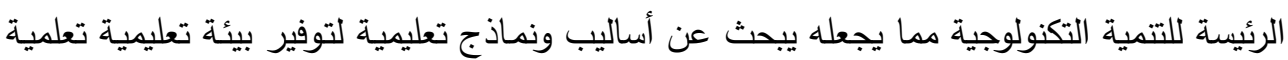
فعالة، فتوجهت الانظمة التعليمية الى استخدام انظمة ادارية حديثة تواكب هذا العصر وتعينها على

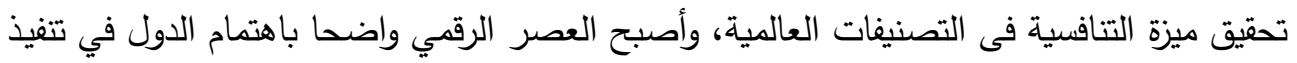

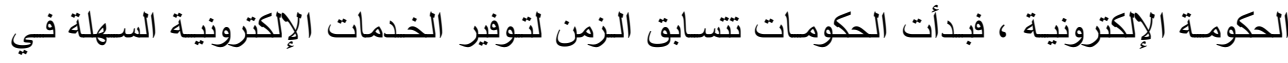

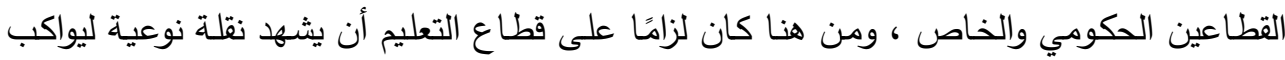

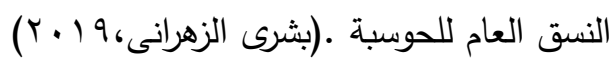

فــع التقدم الكبير في تكنولوجيـا المعلومـات والاتصـالات ، تتغيـر أسـاليب التعليم والتعلم بسرعة وتتأثر بيئات التعلم بشكل كبير وتتحول، والتعلم الإكتروني هو أحد هذه الابتكارات ويرتبط

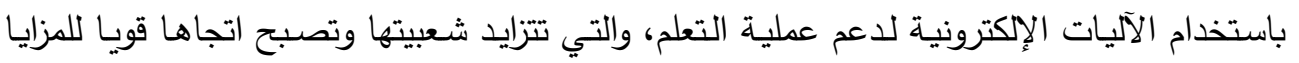
الهائلة التي تقدمها لبيئات التعلم، ومع ذلك، يتطلب نشر أنظمة التعلم الإكتروني وإدارتها استثمارات

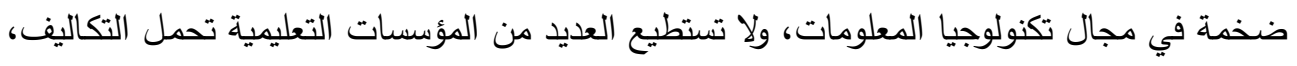

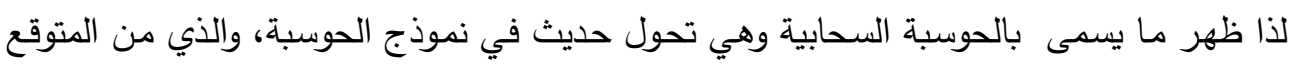

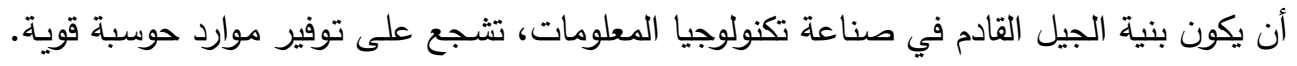

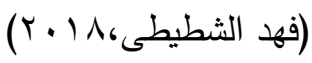


ويرى العديد من الباحثين أن التعلم الالكترني القائم على الحوسبة السحابية، هو الجيل التالي

للتعلم الالكتروني، لذا فان الاتجاه الحديث هو يناء نظام التعلم الالكترونى داخل الحسبة التئ السحابية.

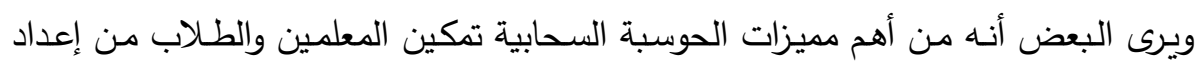

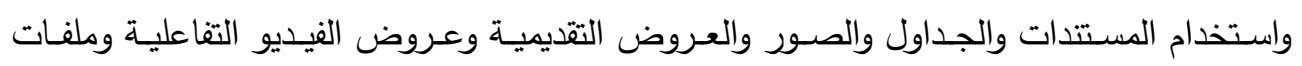

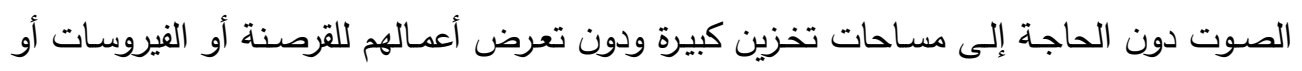

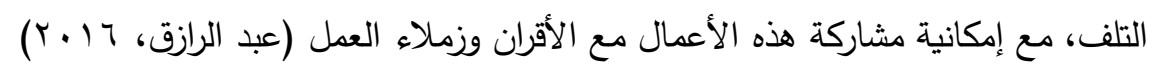
مشكلة البحث:

يواجـه المعلمين فى ظل عصر المعرفـة تسارعًا فى حجم وكمية المعلومـات ممـا يحد من

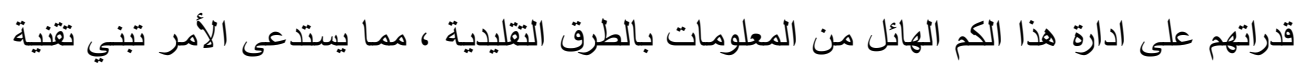

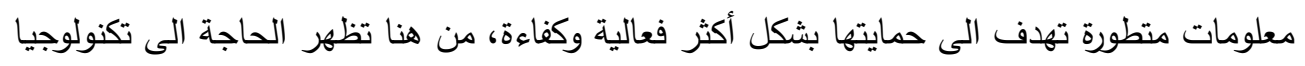

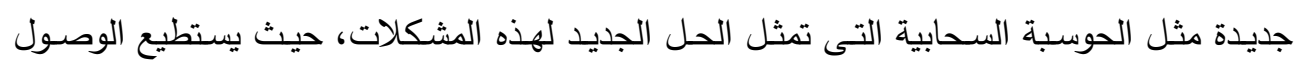

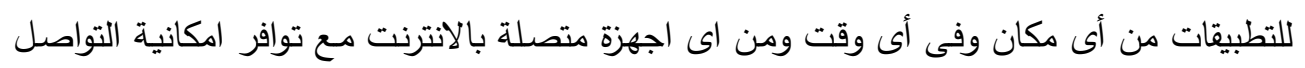

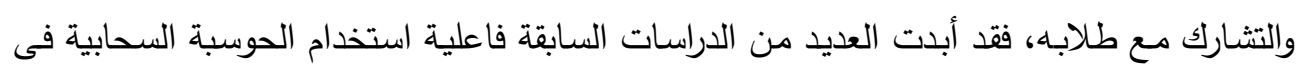

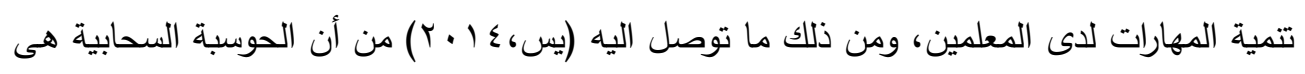

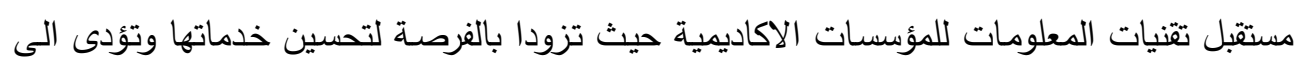
منح المؤسسة أداء ومستقبل أفضل فى مجتمع المعلومات، فقد تعددت المصادر التى يمكن للمعلم

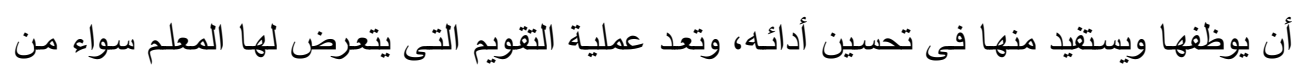

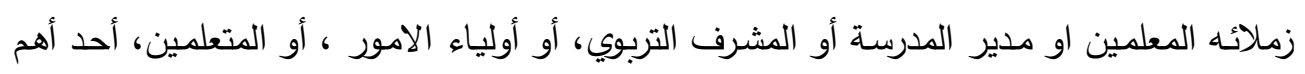

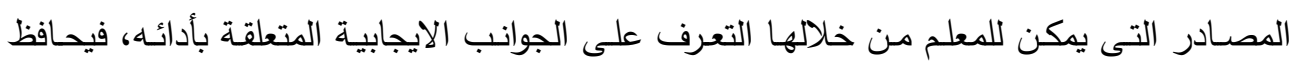

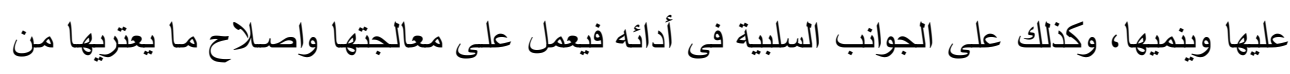
خلل أو نقص، فالحوسبة السحابية تساعد على توافر العديد من التطبيقات المرنه سهلة الاستخدام

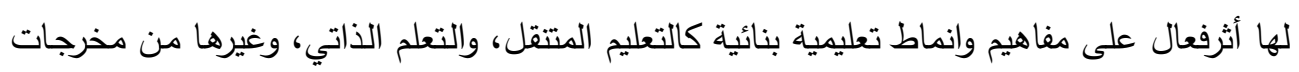

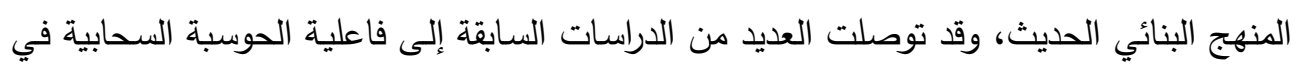

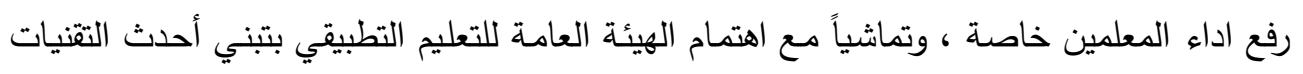

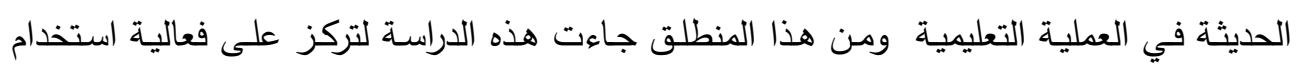

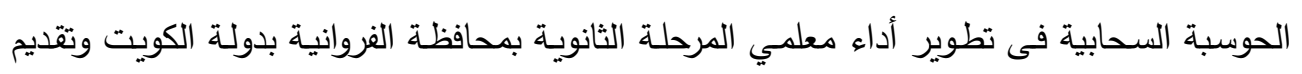
تصور مقترح من المؤمل أن يسهم فى تطوير أدائهم. 
ويحدد السؤال الرئيس للدراسة فيما يلي:

مـا التصور المقترح القائم على الحوسبة السحابية فى تطوير أداء معلمي المرحلة الثانويـة بمحافظة الفروانية بدولة الكويت؟

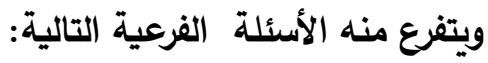

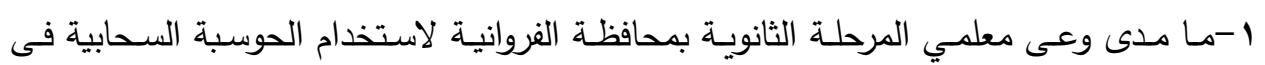

$$
\text { تطوير أدائهم ؟ }
$$

Y-ما معوقات استخدام الحوسبة السحابية لاى معلمى المرحلة الثانوية بمحافظة الفروانية؟

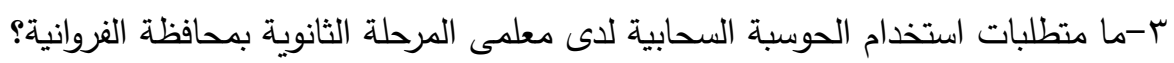

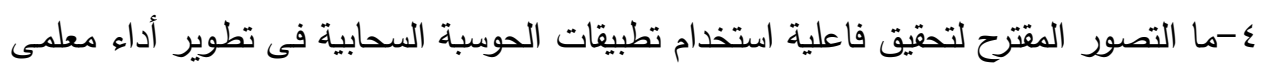

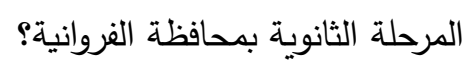
أهية البحث:

1- تعد هذه الدراسة استجابة للتوجيهات الحديثة في مجال تكنولوجيا التعليم والتي تتادي بضرورة

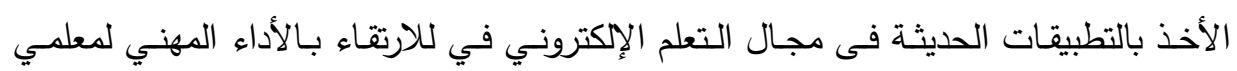
المرحلة الثانوية.

$$
\begin{aligned}
& \text { r- تقسح المجال لدراسات أخرى حول التعلم الإلكتروني وأهميته وفاعليته. } \\
& \text { r- تعزيز الاستفادة من التقنيات الحديثة فى الأداء. } \\
& \text { أهداف البحث: } \\
& \text { هدف هذا البحث الى : }
\end{aligned}
$$

ا - التعرف على مدى فاعلية استخدام الحوسبة السحابية فى تطوير أداء معلىى المرحلة الثانوية

$$
\text { بمحافظة الفروانية؟ }
$$

ץ-التعرف على معوقات استخدام الحوسبة السحابية فى المدارس الثانوية بمحافظة الفروانية ؟

r-التعرف على متطلبات استخدام الحوسبة السحابية فى المدارس الثانوية بمحافظة الفروانية ؟

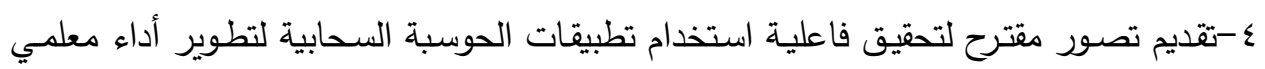

المرحلة الثانوية بمحافظة الفروانية؟

$$
\text { مصطلحات البحث: الترية }
$$

الحوسبة السحابية: وسيلة تعتمد فى عملها على شبكة الانترنت ومراكز البيانات عن بعد، وتقنية المحاكاة الافتراضية، تسمح بتثغيل البرمجيات، والتطبيقات، تخزين البيانات، ومشاركة مواد 
الحوسبة وعرض النطاق الترددي من أماكن بعيدة جغرافياً عن بيئة العميل الحوسبية، بأقل جهد إداري أو تقني، وسرعة فى التحميل والتشغيل أو التعامل مع موفر الخدمة.

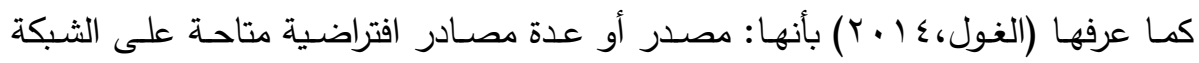

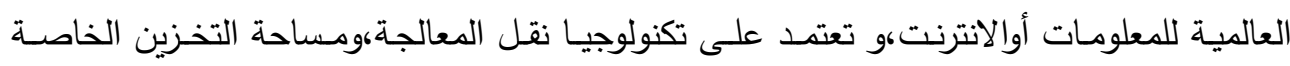

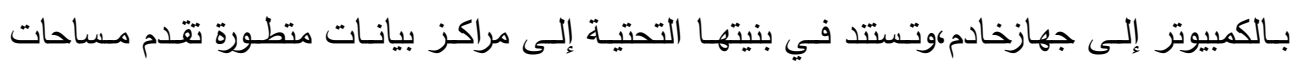

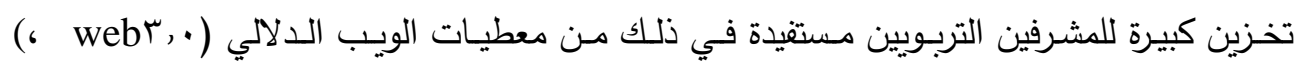

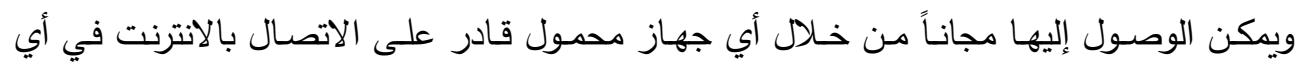
وقت ومن أي مكان.

ويعرفها الباحث اجرائيًا بأنها: نظام خدمى تقني يتيح للمعلمين استخدام التطبيقات وتخزين

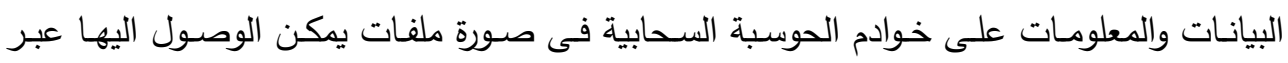
شبكات الانترنت فى كل زمان ومكان مـع إمكانية مشاركتها مـع الادارة المدرسية والطلاب واجراء مناقثات والتواصل التزامني واللاتزامني. محددات البحث:

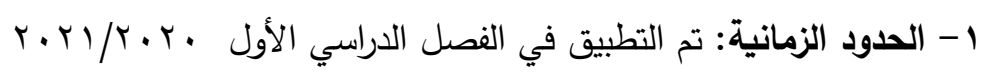
r- الددود المكانية: تتمثل في تطبيق البحث على مدارس المرحلة الثانويـة في محافظة الفروانية بدولة الكويت ب-الحدود البثـرية: تتمثل على عينـة من معلمي المرحلة الثانويـة في محافظة الفروانية بدولـة الكويت ـ - الحدود الموضوعية: تتمثل في التعرف مدى فاعلية استخدام الحوسبة السحابية فى تطوير

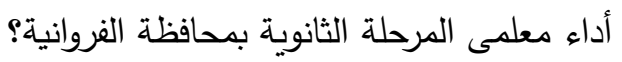
الفصل الثاني الاطار النظري و الدراسات السابقة الحوسبة السحابية:

يعتبر التعليم أو التعلم من أهم عناصـر الحياة، اذ لا يستطيع أى انسان العيش بدون أن

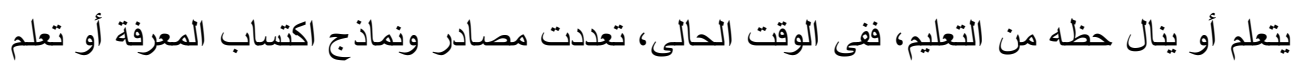
شيئ ما ويعد التعليم الالكتروني من أكثر النماذج الواعدة للتعلم والتعليم، ويعرف التعليم لتعليم الالكتروني

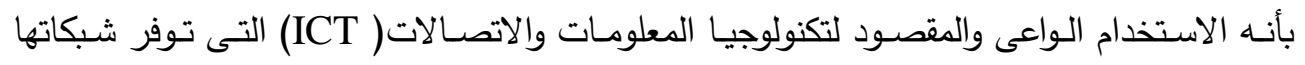
مصادر للتعلم واكتساب المعارف، ويتعاظم الاهتمام بالتعليم الاكتروني نظراً لقدرة نظام تكنولوجيا 
المعلومـات والاتصـالات( ICT) على دعم التعلم والتعليم الـذين يعتمـدان على المـوارد متعـددة

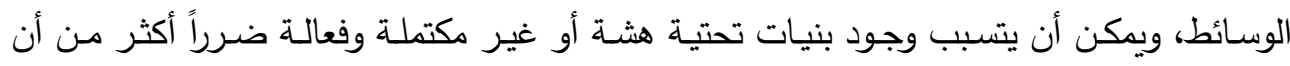
تصيب نفعًا بالنسبة للمعلمين والطلاب وخبراء التعليم، وعلى الرغم من انخفاض تكاليف الأجهزة

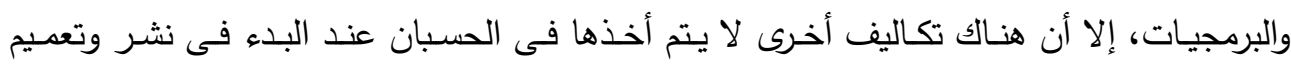
مشاريع التعليم الاكتروني، مثل تكاليف تعزيز البنية التحتية وصيانتها وتدريب الموظفين الأكفاء

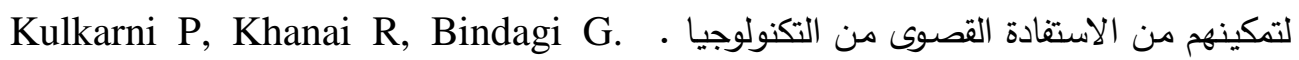

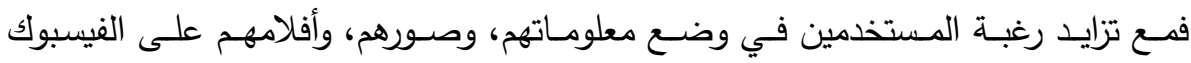

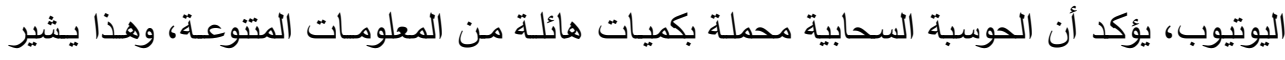

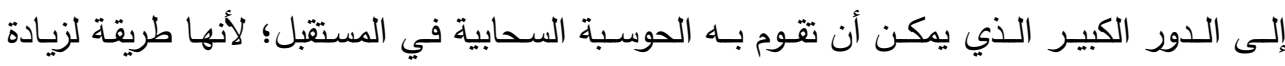

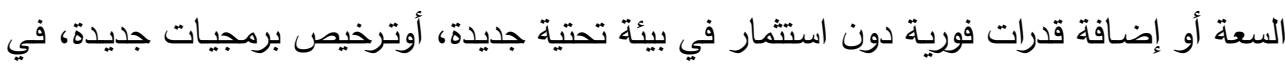

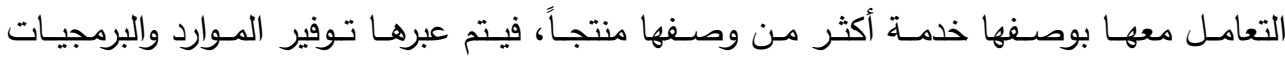
والمعلومات المشتركة لحواسيب أخرى أو أجهزة على أنها أداة عبرالانترنت وفي ظل التعلم الاكترونسي يصبح مـن الضروري رسـم استراتيجيه متميزة لتدفق أوعيـة

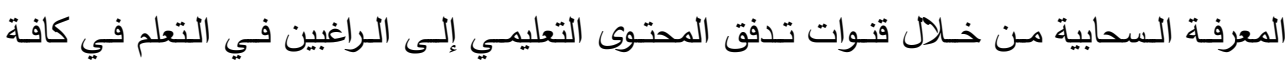

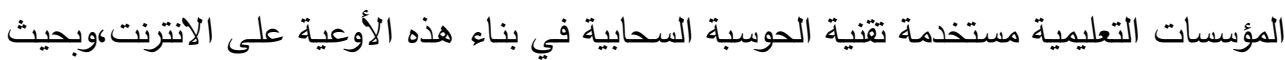

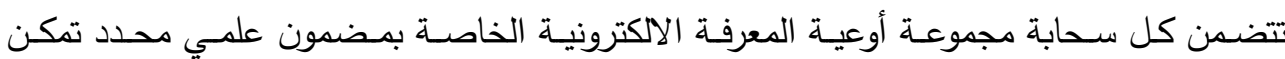

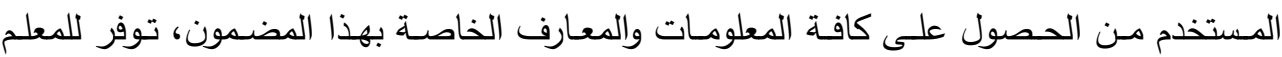

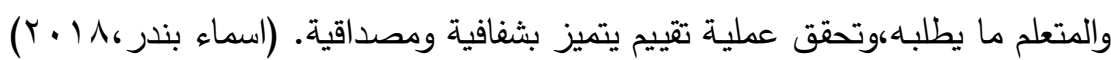

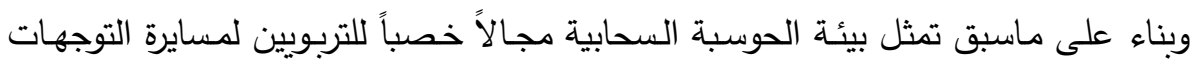

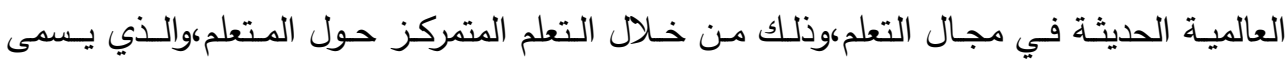

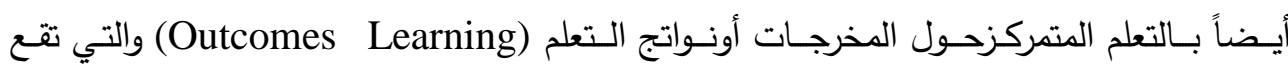
مسئولية تحقيقها على الجميع من متعلم ومعلم ومدير المدرسة والمشرف التربوي.

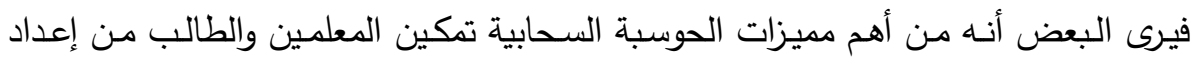

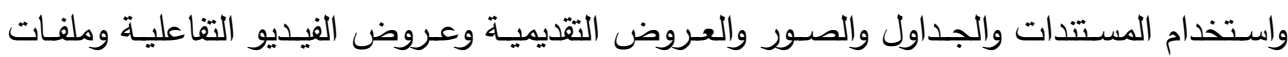

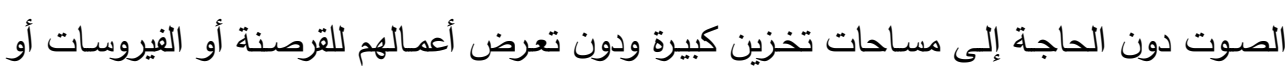

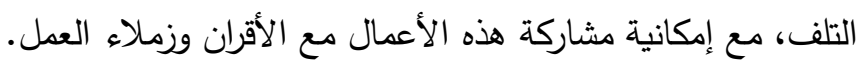




\section{أولاً: مفهوم الحوسبة السحابية:}

الحوسبة السحابية(computing Cloud) تتكون مـن كلمتين الأولى الحوسبة أي أنها مرتبطة بمجال الحاسبات،والثانية السحابية (السحابة) لفظ استخدم للإثـارة إلى الانترنت في البداية

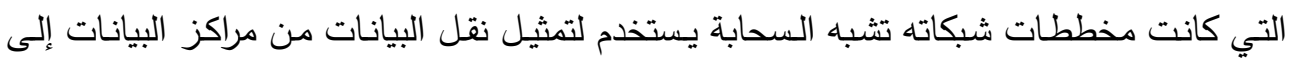

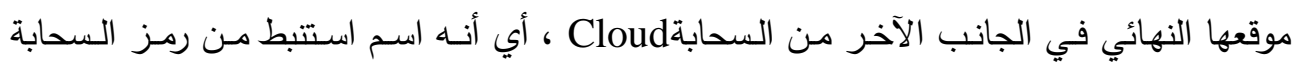
المستعمل لتصوير الشبكات في رسومات تخطيطية فنية.

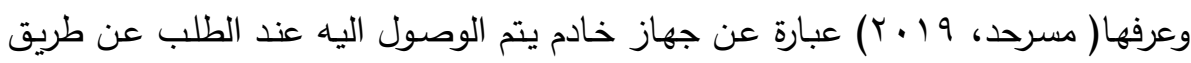

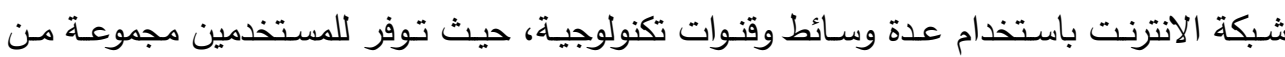
الموارد والخدمات بشكل مرن وسريع مع سهولة فى تبادل البيانات وتثاركها.

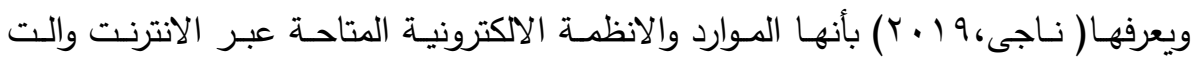

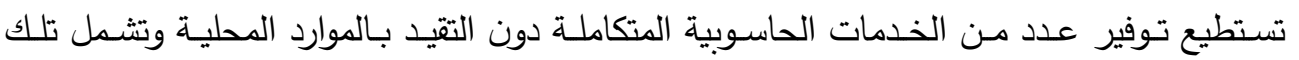
الانظمة مساحة لتخزين البيانات والنسخ الحتياطى والمشاركة والمزامنة الاتوماتيكية.

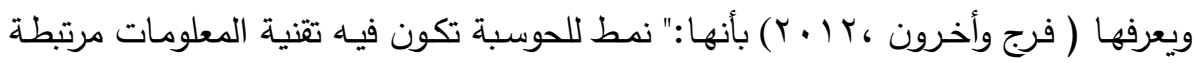
بالقدرات وقابلة للنمو بشكل كبير ،والتي تقدم كخدمة عبر الانترنت إلى عدد من المستخدمين" بانها:

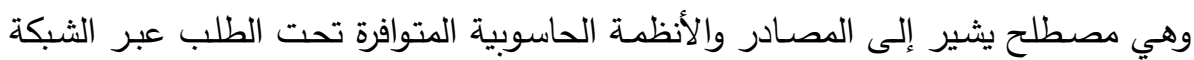

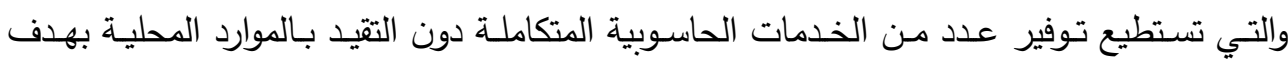

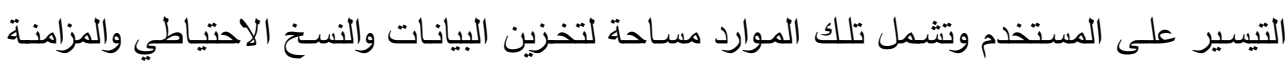

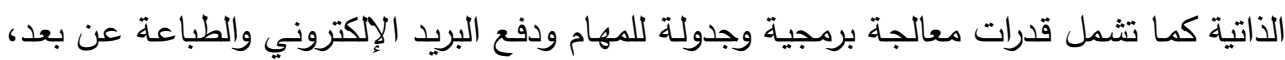
ويستطيع المستخدم عند اتصاله بالثبكة التحكم في هذه الموارد عن طريق واجهة برمجية بسيطة

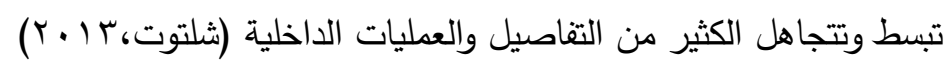
ثانيًا: أهداف الحوسبة السحابية

تهاف الحوسبة السحابية الى تحقيق الغايات التالية: (Kallow,2015) ا-تجعل من الحاسب عبارة عن محطة عبور للوصول الى الخادم الذي يحتوي على مساحة تخزين تمكن المستفيد من التعامل مع بياناته. r- توفير مساحة تخزين للمعلومات عالية الجودة . ب- تتيح الوصول الى المعلومات وسهولة استرجاعها في أي وقت ومن أي مكان تتوفر فيه شبكة الانترنت 
ع - تلغي الحاجة الى عمل نسخ احتياطية للمعلومات المخزنة على الحواسيب الشخصية أو أجهزة

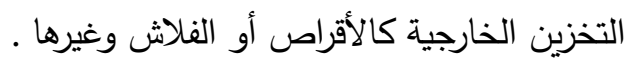
ه-اتاحة معظم البرمجيات التشغيلية والتطبيقية وبصورة مجانية (في أغلب الأحيان) مما يوفر

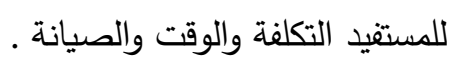

7- توفر عملية المشاركة بالمعلومات بين المستقيدين وسهولة تداولها وتتاقلها عبر شبكة الانترنت بغض النظر عن حجم تلك المعلومات وأشكال ملفات V- توفر للمستفيد امكانية معالجة معلوماته عن بعد والمتعلقة بإنشاء الملفات او حذفها أو اجراء

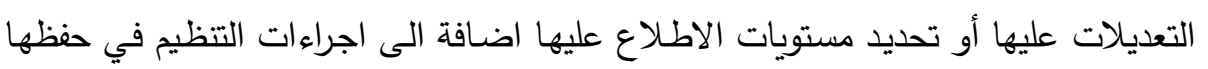

$$
\text { وتخزينها }
$$

ثالثًا: خصائص الحوسبة السحابية

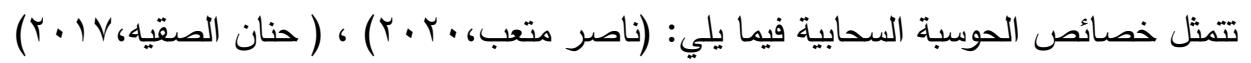

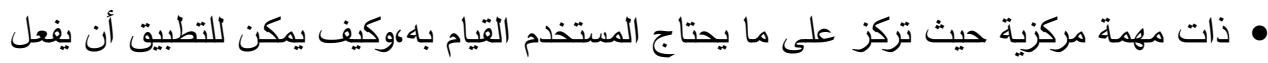
ذلك بالنسبة له. • متشعبة:حيث تربط المئات أوالآلاف من أجهزة الحاسب معاً في السحابة،ولا تقتصر على بلى مصدر واحد من البيانات. • متعددة الإيجـار : يمكن تقاسم الموارد والتكاليف عبر مجموعـة كبيرة من المستخدمين.

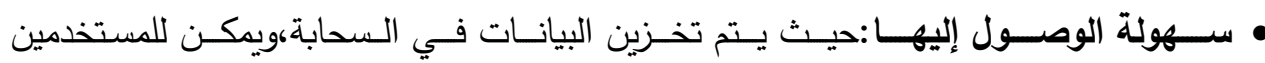
الاسترداد الفوري لمزيد من المعلومات من مستودعات متعددة.

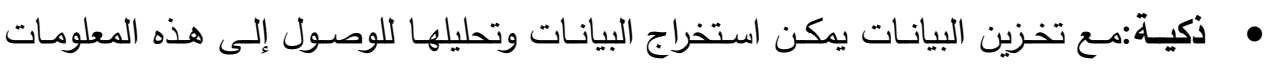
بطريقة ذكية. • الحوسبة السحابية أرخص وأسرع وتتسم بالبيئة النظيفة، دون أي استثمارات في البنيةالأساسية

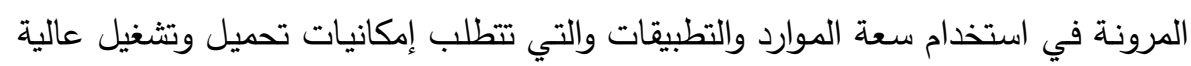

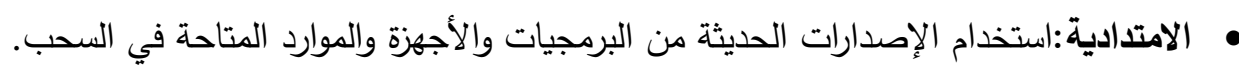
رابعا: نماذج تصميم تقنية الحوسبة السحابية :

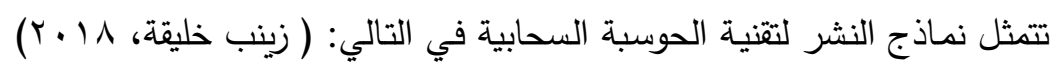

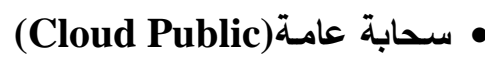




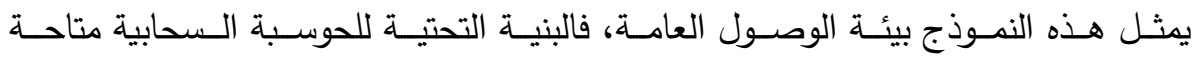
للعامـة،ويمكن لأي شخص الدخول إليها ومملوكة لمنظمة بيع خدمات سحابية.

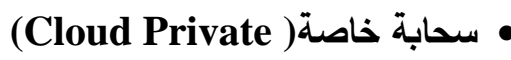

تمثل شبكات خاصة،وتبني لاستخدام جهة معينة،وتوفر مراقبة كاملة للبيانات،وضمان الأمن وجودة البيانات

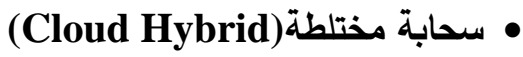

تتكون مـن سـابتين أوأكثر (عامـة وخاصـة أو عامـة ومجتمعيـة) لها مكونـات مميزة، ولكن ترتبط معاً بتقنية معينة تساعد على الوصول للبيانات والتطبيقات .

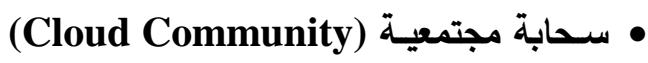

تعتمــ على مسشاركة مـن عـدة منظمـات،وتـدعم مجتمـع معسين لـه اهتمامـات مسشتركة مثل(متطلبات الأمن، الإتاحة، سهولة توافر وتدفق البيانات خامسًا: تطبيقات الحوسبة السحابية في العملية التعليمية:

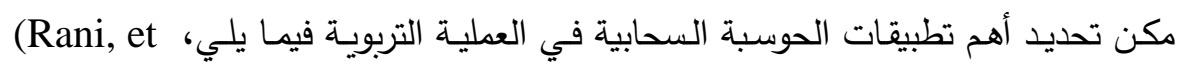

(Ahmed, \& Bora,2013)؛al.,2013)

1- تساعدالمتعلمين على إجراء الاختبارات على الخط (Online) وإلغاءها بعد نهاية الفصل. ץ- عمـل حسابات لـلآلاف مـن المعلمـين والمتعلمـين لتـدريبهم أوتتميـتهم مهنيـاً أو اسـتقبال

$$
\text { مشاريعهم. }
$$

$$
\text { ץ- سهولة إرسال التدريبات والمشروعات للمعلمين والمتعلمين }
$$

r- سهولة وصول المعلمين للتدريبات الخاصـة بهم والمشروعات المقدمة لهم من المتعمين . ع - سهولة التواصل بين المشرفين التربويين والمعلمين والمتعلمين.

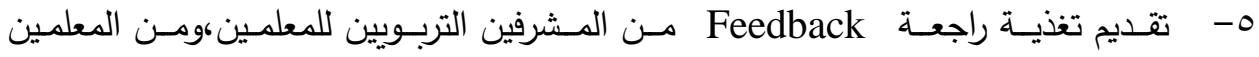

$$
\text { للمتعلمين }
$$

$$
\text { 7-المساعدة في تعليم المتعلمين بطرق جديدة . }
$$

V - تساعدالمشرفين التربويين والمعلمين والمتعلمين من الوصـول للملفات المخزنة بـدون تحميل

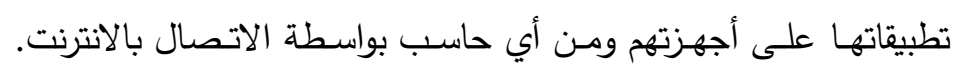

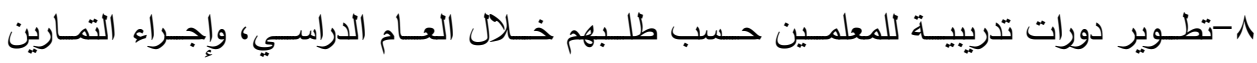

$$
\text { والأنثطة التعليمية من خلال الويب دلتيب لمعلين }
$$




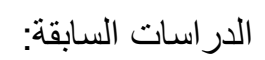

تناولت العديد من الدراسات المتطلبات المهنية والإكترونية أو التكنولوجية التي تحتل مكانة مهمة في الأدب التربوي الحديث وذلك لأهميتها بفاعلية التدريس والتعليم ،وقدرة المعلم علي القيام

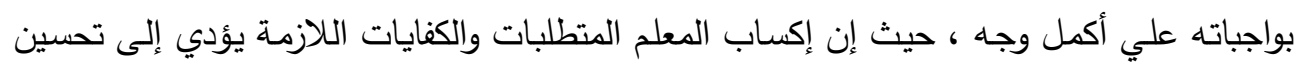

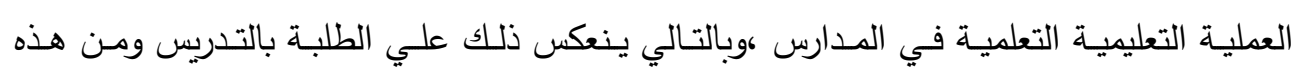
الدراسات ما يلي:

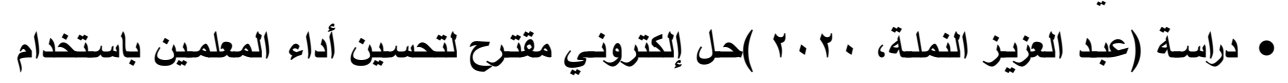
تقنية الحوسبة السحابية وشبكات التواصل الاجتماعية

هدف هذا البحث إلى بناء وتطبيق حل الكتروني مقترح لتحسين أداء المعلمين باستخدام تقنية الحوسبة السحابية، وشبكات التواصل الاجتماعية. ولتحقيق أهداف البحث؛ تم استخدام المنهج

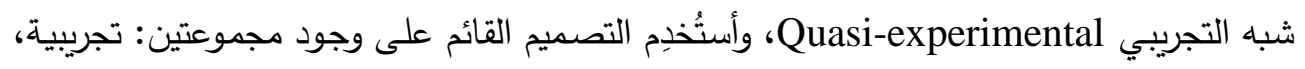

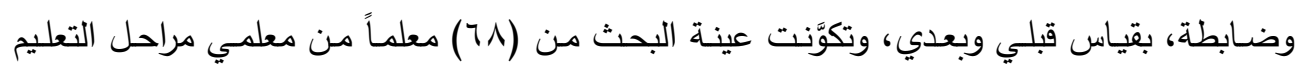

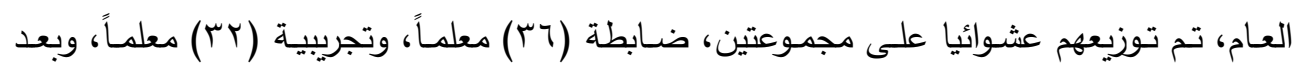

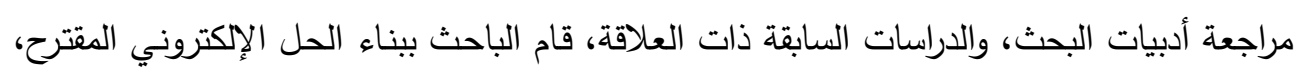

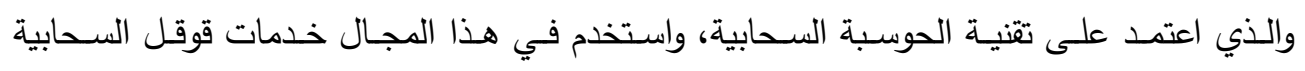

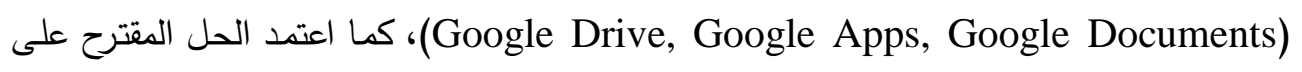
شبكات التواصل الاجتماعي، واستخدم تطبيق واتس آب (WhatsApp). وبعد التأكد من خطوات

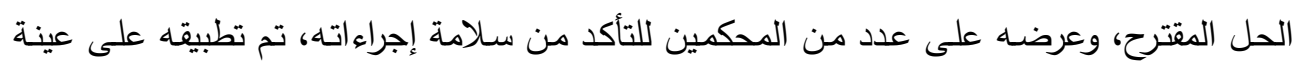

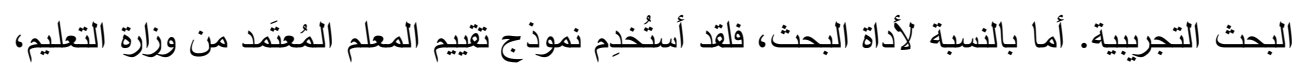
والمتوفر في أنظمـة الوزارة الإكترونية (نور )، والمستخدم من قبل المشرفين التربويين لقياس أداء

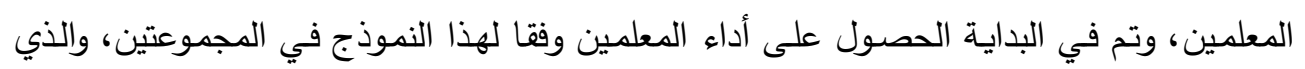

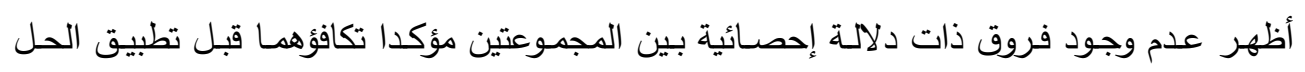

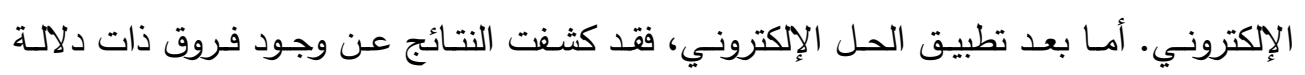

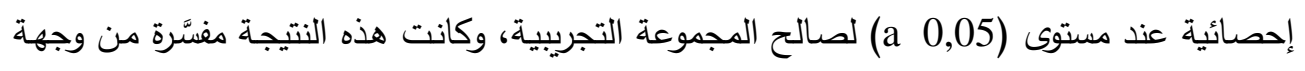
نظر الباحث في ظل ما سيوفره الحل الإكتروني من دعم وتغذية راجعة متخصصة ودقيقة للمعلم

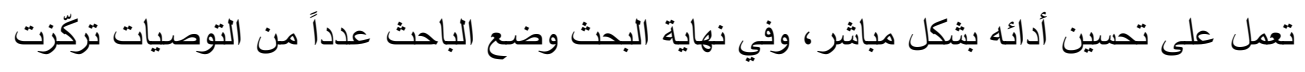


على الاستمرار في تقديم الحلول الإلكترونية العصرية، وتفعيل استخدامها في الميدان التعليمي، بعد التأكد من آثارها الايجابية من خلال دراسات التقصي على متغيرات البيئة التعليمية.

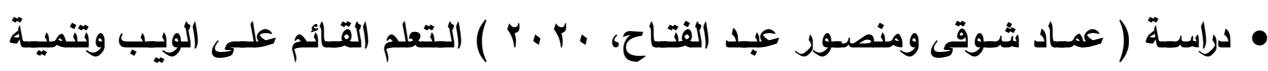

استخدام بعض تطبيقات الحوسبة السحابية

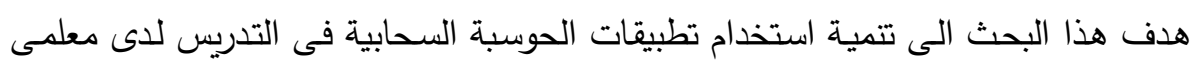

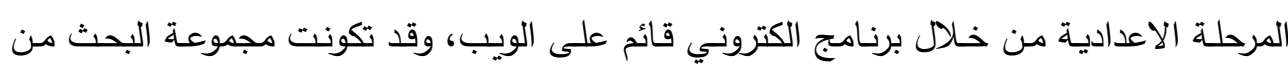

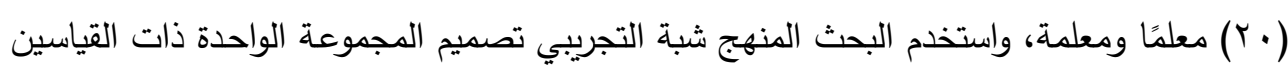
القبلي والبعدى، أعدت قائمة بمهارات استخدام تطبيقات الحوسبة السحابية التى ينبغي تتميتها لدى

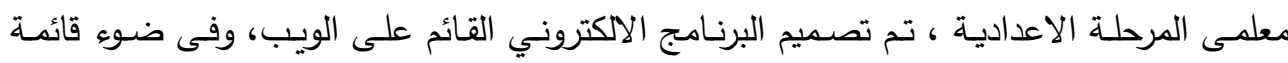

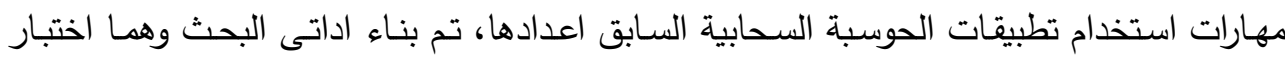

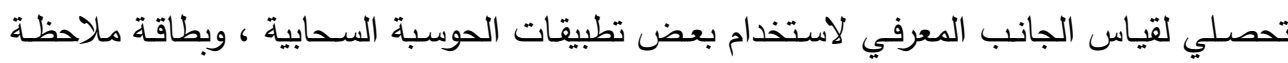

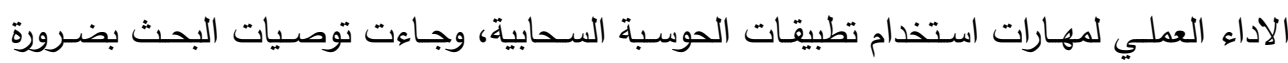

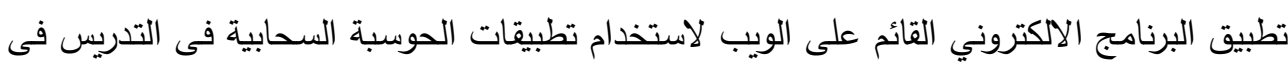
البرامج التدريبية للمعلمين.

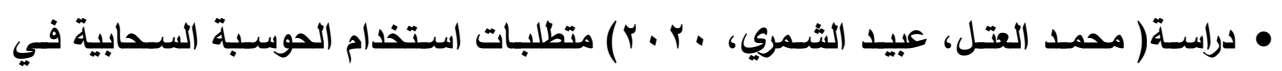
تدريس مقرر الحاسوب من وجهة نظر المعلمين قبل الخدمة في دولية الكويت واتجاهاتهم نحوها. هدفت الدراسـة إلى التعرف على متطلبات استخدام الحوسبة السحابية في تدريس مقرر الحاسوب من وجهة نظر المعلمين قبل الخدمة في دولة الكويت واتجاهاتهم نحوها؛ وأثر متغيري

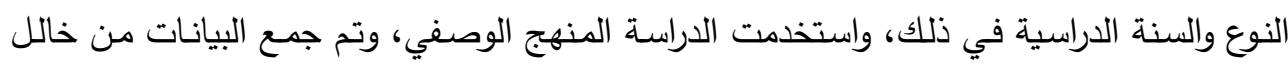

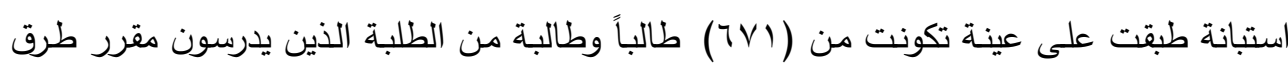
تدريس الحاسوب بكلية التربية الأساسية، وأظهرت النتائج وجود اتجاهات إيجابية لدى أفراد عينة

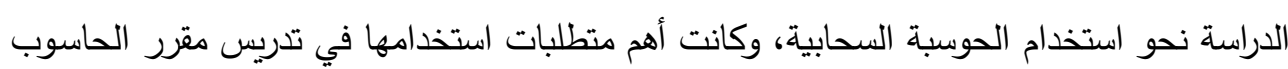

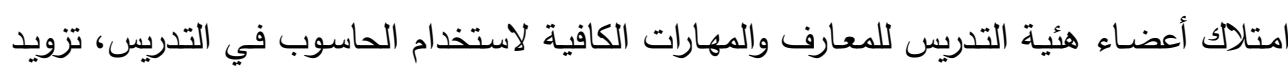
الطلبـة بعنـاوين الحسـابات التي يمكنهم التواصـل معها ومشـاركة المستتندات مـن خلالهـا، توفير إجراءات الأمان للحسابات المتعلقة باستخدام تطبيقات الحوسبة السحابية، نشر الوعي بأهمية وفوائد

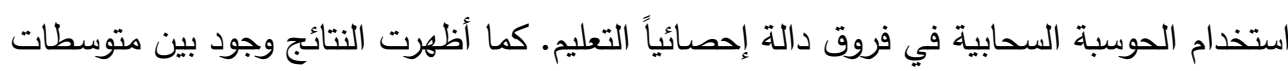


أفراد عينـة الدراسـة حول متطلبات استخدام الحوسبة السحابية في تدريس مقرر الحاسوب تعزى لمتغير النوع لصالح الذكور، بينما لا توجد فروق حول اتجاهاتهم نحو استخدام الحوسبة السحابية تعزى لمتغير النوع، كما أظهرت النتائج عدم وجود فروق حول متطلبات استخدام الحوسبة السحابية في تدريس مقرر الحاسوب، واتجاهات أفراد عينة الدراسة نحوها تعزى لمتغير السنة الدراسية.

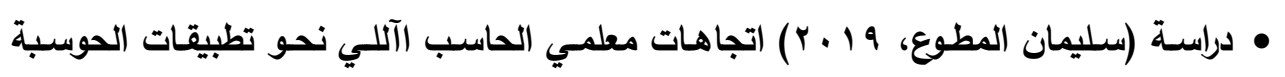

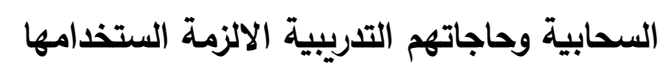

هدفت إلى التعرف على اتجاهات معلمي الحاسب آللي نحو تطبيقات الحوسبة السحابية في

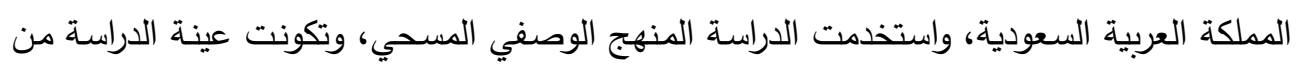

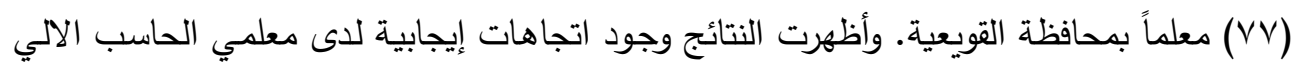
نحو تطبيقات الحوسبة السحابية، كما أظهرت النتائج وجود فروق ذات دلاتلة إحصائية في اتجاهات

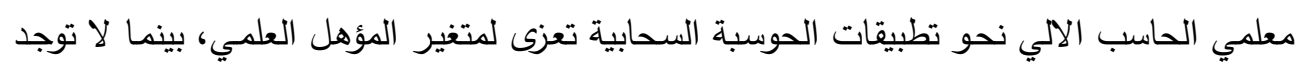
فروق تعزى لمتغيري الخبرة وعدد الدورات التدريبية الفصل الثالث إجر اءات البحث التث

يتضمن هذا الفصل وصفًا للاجراءات التى اتبعها الباحث من أجل تحقيق هدف البحث، اذ اذ

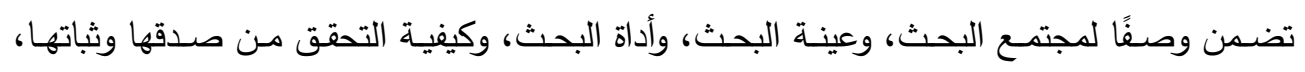

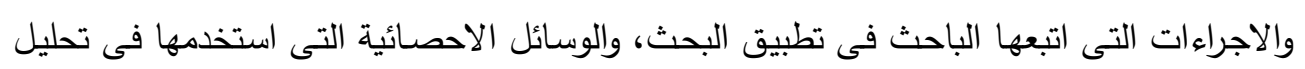

$$
\text { أولاً: منهج البحث: النتج: }
$$

ان اختيار منهج البحث الذى يتبناه الباحث فى اجراءات الدراسة، وتحليلاته يأتى فى مقدمة

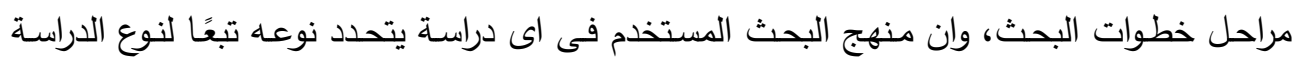

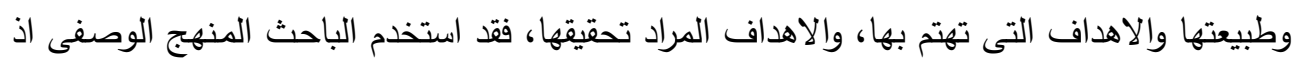
انه المنهج الملائم لطبيعتها، والذى من خلاله يتم جمع المعلومات عن الظاهره( موضوع الدراسة) ومن ثم وصفها وصفًا كميًا ونوعياً. ثانيًا: مجتمع البحث وصغها وصغا كميًا ونوعياً

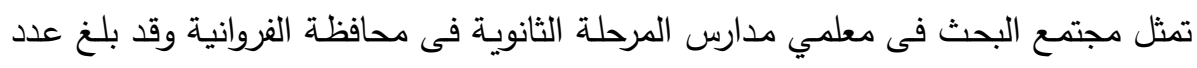

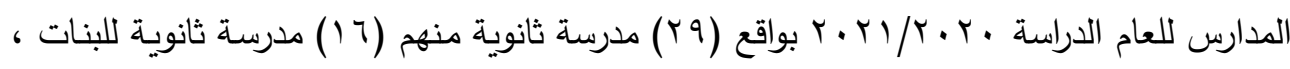

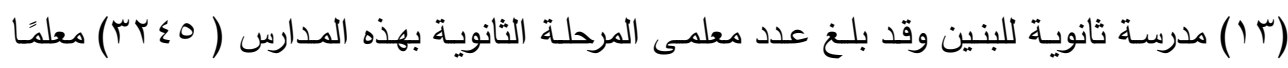




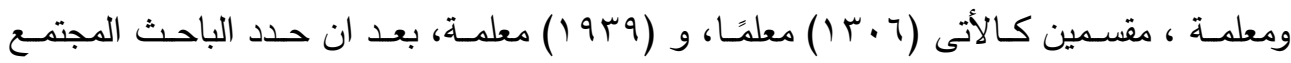

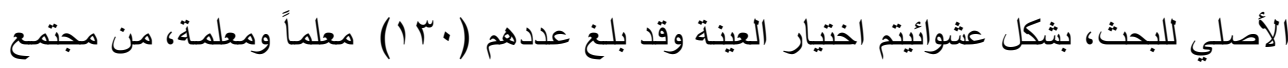
البحث الاصلي، وقد قام بتوزيع الاستبانه على أفراد العينة وجمعها.

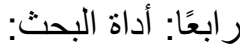

ان اداة البحث تحدد بحسب طبيعة البحث ومستلزماته؛ لأن استخدام الاداة المناسبة يؤدي

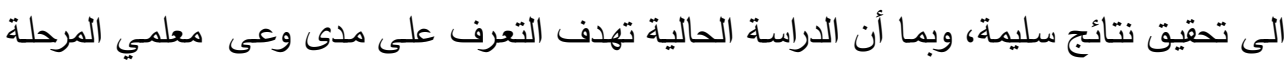

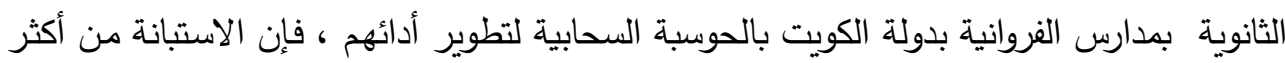

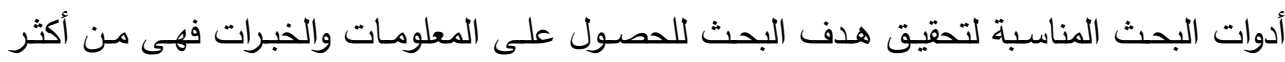
ادوات البحث التربوي شيوعًا وانتشارًا وتحقيقًا لأهداف البحث أعد الباحث، فقد اشتملت الاستبانة على ثلاث محاور تضمنت (مدى وعى المعلم بالحوسبة السحابية- معوقات استخدام المعلمين للحوسبة السحابية- متطلبات استخدام الحوسبة السحابية فى تطوير أداء المعلمين) خامسًا:الاساليب الاحصائية المستخدمة: استخدم الباحث التحليل الاحصائي Spss لبيانات الاستبانه المقدمة للعينة البحثية.

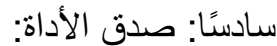
الصدق شرط أساسي ضرورى يجب توافره فى الأداة التى يستخدمها الباحث، وقد قام الباحث

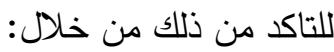

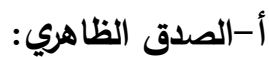

للتعرف على مدى صدق أداة الدراسة فى قياس ما وضعت لقياسه تم عرضها على عدد من

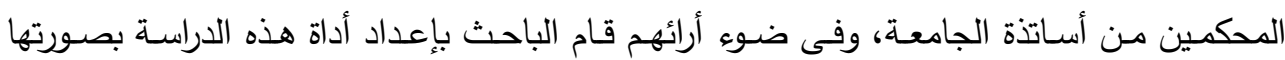
النهائية.

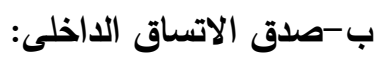
بعد التاكد من الصدق الظاهري لأداة الدراسة قام الباحث بتطبيقها ميدانيًا وعلى ضوء بيانات العينة قام الباحث بحساب معامل الارتباط بيرسون لمعرفة الصدق الداخلي للاستبانة حيث تم حساب معامل الارتباط بيرسون بين درجة كل عبارة من عبارات الاستبانة بالدرجة الكلية للمحور الذي لإني تتنمي اليه العبارة ويتضح ذلك من خلال الجداول التالية والتى توضح ارتباط كل محور من المحاور مع عباراته: 


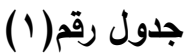

معاملات ارتباط بيرسون لارتباط كل فقرة من فقرات الاستبيان مع درجة المحور الذي تتنمي

إليه بالمحاور الثلاثة

\begin{tabular}{|c|c|c|c|c|c|c|c|}
\hline المجال & الفقرة & معامل الارتباط & مستوى الدالة & المجال & الفقرة & معامل الارتباط & مستوى الدلالة \\
\hline \multirow{11}{*}{ 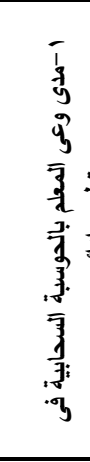 } & 1 & דוג, & $\cdot, .1$ & \multirow{21}{*}{ 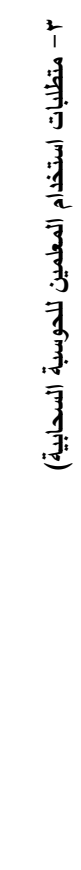 } & 1 &., $9 \wedge \vee$ & $\cdot, \cdot 1$ \\
\hline & $r$ & •, AVY &., .1 & & r & •, &., .1 \\
\hline & $r$ & $\cdot, \wedge \backslash \wedge$ &., .1 & & $r$ & $\cdot, \wedge \vee 1$ &., .1 \\
\hline & $\varepsilon$ & $\cdot, \wedge \vee \wedge$ &., .1 & & $\varepsilon$ & $\cdot, \vee \vee \wedge 9$ &., .1 \\
\hline & 0 & .,var &., .1 & & 0 & $\cdot, \mathrm{v} \wedge \mathrm{r}$ &., .1 \\
\hline & 7 & ., $\vee$ q. &., .1 & & 7 & $\cdot, \Lambda \cdot r$ &., .1 \\
\hline & $\mathrm{v}$ & 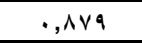 &., .1 & & $v$ &., 709 &., .1 \\
\hline & $\wedge$ & ., $\vee \wedge$ 。 &., .1 & & $\wedge$ & | &.,., 1 \\
\hline & 9 & $\cdot, \mathrm{VAr}$ &., .1 & & 9 & $\cdot, \Lambda \cdot r$ &., .1 \\
\hline & 1. & $\cdot, \wedge \cdot r$ &., .1 & & 1. & $\cdot, \wedge \backslash \wedge$ &., .1 \\
\hline & 11 & $\cdot, \wedge 11$ &., .1 & & & & \\
\hline \multirow{10}{*}{ 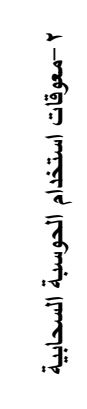 } & 1 & $\cdot, \wedge \cdot r$ &., .1 & & & & \\
\hline & $r$ & $\cdot, \vee \vee 9 \wedge$ &., .1 & & & & \\
\hline & $r$ & $\cdot, \wedge 11$ & $\cdot, \cdot 1$ & & & & \\
\hline & $\varepsilon$ & - 9 , & $\cdot, ., 1$ & & & & \\
\hline & 0 &., $7 Y \leq$ &., .1 & & & & \\
\hline & 1 & $\cdot, \wedge \vee \leqslant$ &.,+1 & & & & \\
\hline & v &., 9.1 &.,+1 & & & & \\
\hline & $\Lambda$ & $\cdot, v \leqslant 0$ &., .1 & & & & \\
\hline & 9 & $\cdot, \wedge \vee q$ &., .1 & & & & \\
\hline & 11 & $\cdot, \wedge \circ \leq$ &., .1 & & & & \\
\hline
\end{tabular}

يتبين من الجدول السـابق أن جميع فقرات استبيان مدى وعى المعلمين بمدارس المرحلة

الثانوية بدحافظة الفروانية بالحوسبة السحابية وما هى معوقات استخدامها وما هى متطلبات تفعيلها للمساعدة فى تطوير أداء المعليمن وقد اشتملت الاستبانة(r فقرة) حققت ارتباطات دالة مـع درجة

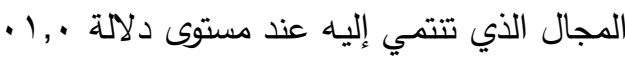
سادسًا: ثبات الأداة:

اعتمد الباحث على مقياس الفا كرونباخ للتأكد من ثبات أداة الدراسة .

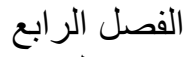
عرض النتائج وتفسير ها

يتضمن هذا الفصل النتائج التي تم التوصل إليها في هذه الدراسة، وذلك بعد التحقق من السؤال الرئيس للاراسة بمجالاته باستخدام الأساليب الإحصائية المناسبة لكل منها، وقد تم تفسير ومناقتشة النتائج التي تم التوصل إليها في ضوء الإطار النظري والدراسات السابقة: 
1- مـا مدى وعى معلمي المرحلـة الثانويـة بمحافظـة الفروانيـة لاستخدام الحوسبة السحابية فىى

$$
\text { تطوير أدائهم ؟ }
$$

للإجابة عن هذا السؤال قام الباحث باستخدام المتوسط الحسابي والانحراف المعياري والوزن

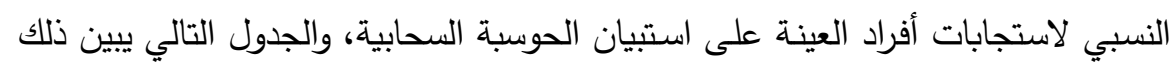

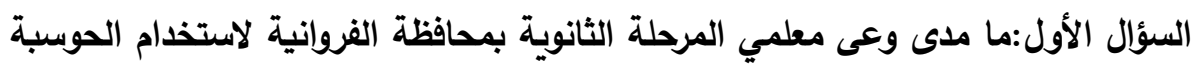

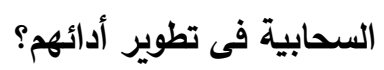

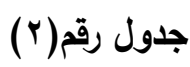

المتوسط الحسابي والانحراف المعياري والوزن النسبي لاستجابات أفراد العينة على مدى ولى

\begin{tabular}{|c|c|c|c|c|}
\hline الترتيب & العبارة & الحسابوسط & النسبي & المعياري \\
\hline 1 & استخدام الحوسبة السحابية يساعد في الحصول على المعلومات بشكل أسرع & 3.99 & 0.80 & 1.118 \\
\hline r & المستطهفيعة. توظيف ملفات PowerPoint) بالدوسبة السحابية في معرفة نــواتج الــتعلم & 3.96 & 0.79 & 1.213 \\
\hline$r$ & لايى معرفة بالتطبيقات السحابية مثل (Google Docs) & 3.77 & 0.75 & 1.265 \\
\hline$\varepsilon$ & توفر خدمات الحوسبة السحابية بيئة استخدام مناسبة وآمنة في المجال التعليمي. & 3.87 & 0.77 & 1.135 \\
\hline 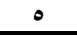 & 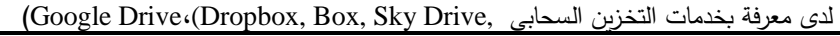 & 3.87 & 0.77 & 1.228 \\
\hline 1 & لدى معرفة الفرق بين السحب العامة والخاصة والهجين & 3.63 & $\mathbf{0 . 7 3}$ & 1.196 \\
\hline $\mathrm{v}$ & الاتصال وتقنية المعلومات السحابية يجعل تدريس مقرر الحاسوب مواكباً للتطورات المتسارعة لوسائل & 4.26 & 0.85 & 1.171. \\
\hline$\wedge$ & 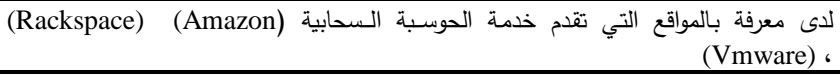 & 3.77 & 0.75 & 1.267 \\
\hline 9 & 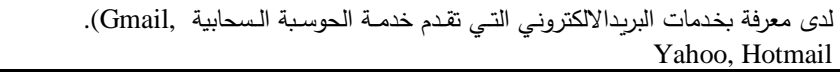 & 4.02 & 0.80 & 1.232 \\
\hline 1. & 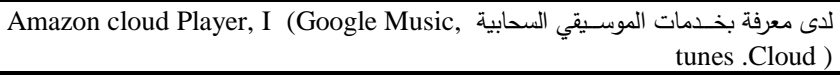 & 3.87 & 0.77 & 1.135 \\
\hline 11 & لاى معرفة بأنظمــة التـشغيل السحابية , Jolicloud। \&, Google Chrome Os ) & 3.62 & 0.72 & 1.195 \\
\hline
\end{tabular}

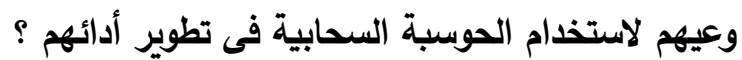

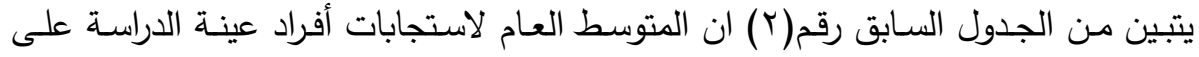

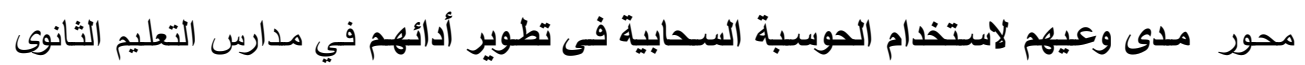

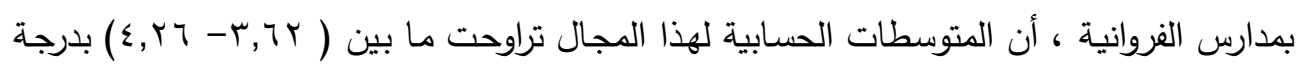
متوسطة وقد احتلت العبارة (V) والتي تتص على: استخدام الحوسبة السحابية يجعل تدريس مقرر

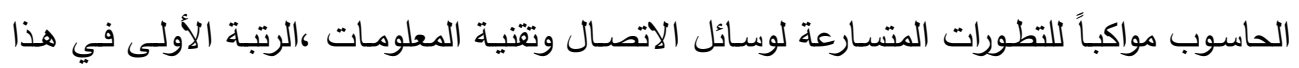

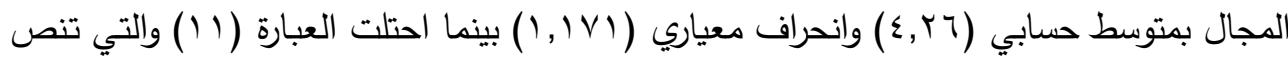

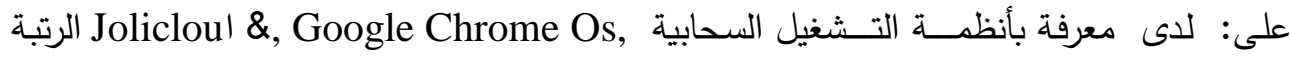

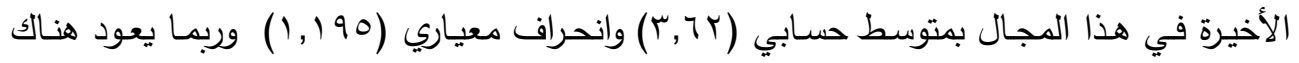


قصور لاى المعلمين بمعرفتهم بالحوسبة السحابية وعدم معرفتهم الكاملة بانظمة التشغيل المرتبطة

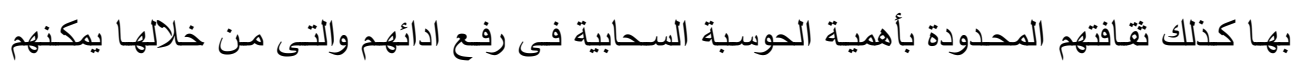

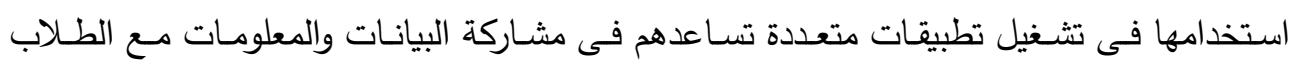
وزملائهم المعلمين وكذلك الادارة المدرسية، كما ان بعض العبارات السابقة اثبتت وجود اتجاهات فئسات إيجابية لاى أفراد عينة الدراسة نحو الحوسبة السحابية، حيث تجعل تدريس مقرر الحاسوب مواكباً

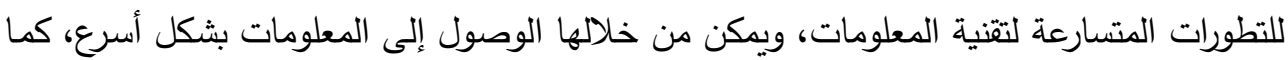

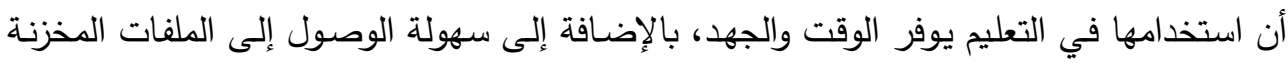

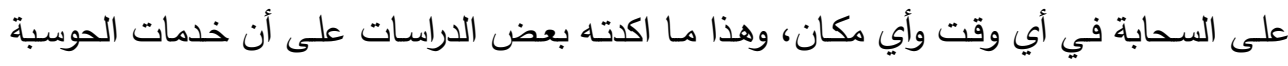

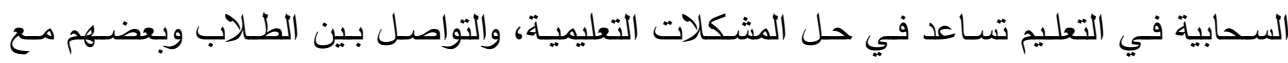
اختلاف أماكنهم لتحقيق أهداف محددة بأقل وقت وتكلفة ومن أي حاسوب أو جهاز نقال. السؤال الثاني: مـا معوقـات استخدام الحوسبة السـحابية لـدى معلمس المرحلـة الثانويـة

بمحافظة الفروانية؟

\section{جدول رقم) (r)}

المتوسط الحسابي والانحراف المعياري والوزن النسبي لاستجابات أفراد العينة على المعوقات

استخدام الحوسبة السحابية لايهرم

\begin{tabular}{|c|c|c|c|c|}
\hline الترتيب & 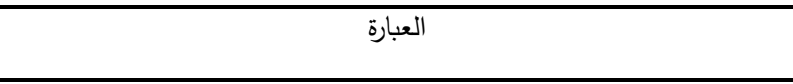 & 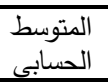 & 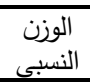 & 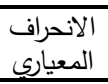 \\
\hline 1 & لمادته قناعة المعلمين باستخدام الحوسبة السحابية وارتباطها بنواتج التعلم & 3.61 & 70.3 & 1.51 \\
\hline r & 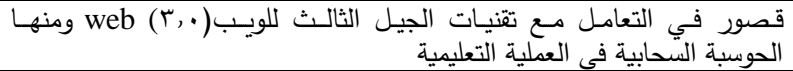 & 3.60 & 70.01 & 1.50 \\
\hline r & صعوبة الوصول إلى المعلومات عند وجود عطل في الموقع أو شبكة الاتصال & 3.60 & 70.01 & 1.50 \\
\hline$\varepsilon$ & 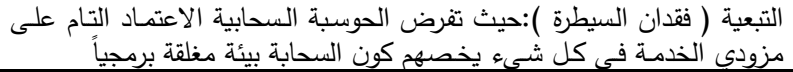 & 3.72 & 73.2 & 1.51 \\
\hline ० & 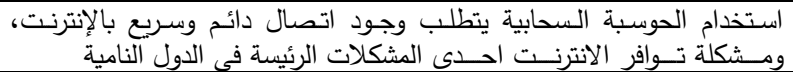 & 3.68 & 71 & 1.50 \\
\hline 7 & 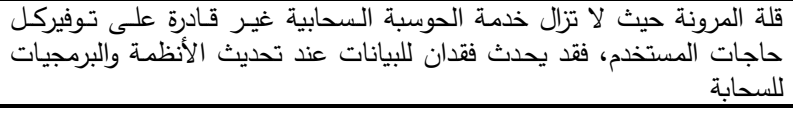 & 3.61 & 70.3 & 1.51 \\
\hline $\mathrm{V}$ & روتينية المعلمين وعدم الرغبة فى مواكبة التجديد التطوير & 3.19 & 67.00 & 1.41 \\
\hline$\Lambda$ & جمودية القرارات المرتبطة بالتطوير واسخدام التكنولوجيا & 3.59 & 70.00 & 1.50 \\
\hline 9 & السحابية وجود متخصصين فى شبكة المعلومات يساعد فى استمرار العمل بالحوسبة & 4.11 & 76.6 & 1.56 \\
\hline 1. & عدم قناعة اصحاب القرار بالحوسبة السحابية & 4.31 & 84.2 & 1.58 \\
\hline 11 & ضعف الدعم المالى الخاص بالتطور التكنولوجى & 4.30 & 84.01 & 0.580 \\
\hline
\end{tabular}


يتبين من الجدول السـابق رقم(؟) ان المتوسط العـام لاستجابات أفراد عينـة الدراسـة على

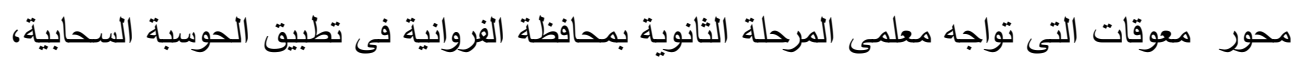

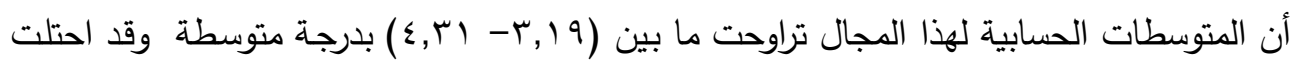

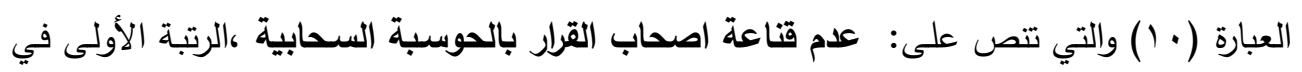

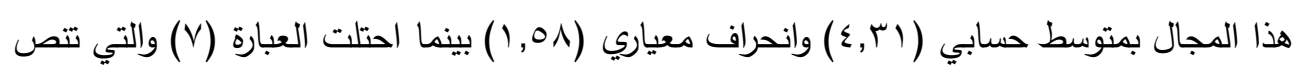

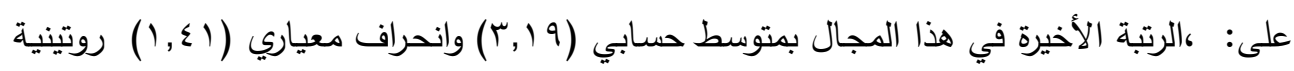

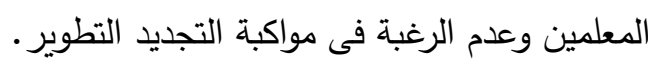

السؤال الثالث متطلبات استخدام الحوسبة السحابية لمعلمى مدارس التعليم الثانوى

بمحافظة (لفروانية)

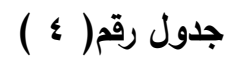

استجابات افراد العينة على عبارات المحور الثالث متطلبات استخدام الحوسبة السحابية لمعلى مدارس التعليم الثانوى بمحافظة الفروانية)

\begin{tabular}{|c|c|c|c|c|}
\hline الترتيب & العبارة & المتوسط الحسابي - ابي & 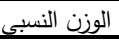 & الانحراف المعياري \\
\hline 1 & نشر الوعى باهمية استخداج الحوسبة السحابية في التعليم & 3.61 & 70.3 & 1.04 \\
\hline r & عمل دليل إرشادي لاستخدامات الحوسبة السحابية في التعليم & 3.64 & 71.0 & 1.08 \\
\hline$r$ & ضراسوب في التدرب. المعلمين للمعارف والمهارات الكافية لاستخدام & 3.60 & 70.0 & 1.04 \\
\hline$\varepsilon$ & 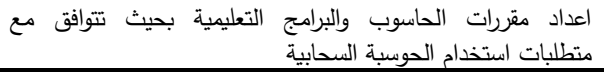 & 3.72 & 73.2 & 1.05 \\
\hline - & 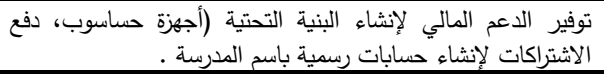 & 3.59 & 70.00 & 1.03 \\
\hline 1 & باستخدام الحوسبة الدحابية ونشرها عبر التحيح الاختبارات وتصحيحها & 28.4 & 84.00 & 1.17 \\
\hline $\mathrm{v}$ & تبنى المدارس الثانوية خدمة الحوسية السحابية على أجهزتها & 4.21 & 83.6 & 1.22 \\
\hline$\Lambda$ & توفير المواد اللازمة لاستخدام تطبيقات الدوسبة السحابية & 4.11 & 76.6 & 1.16 \\
\hline 9 & متابعة كل ما هو جديد فى استخدام التطبيقات وتحديثاتها. & 4.12 & 76.9 & 1.18 \\
\hline 1. & استخدام سحب مجتمعية تحت مظلة وزارة التعليه & 4.16 & 77.00 & 1.23 \\
\hline
\end{tabular}

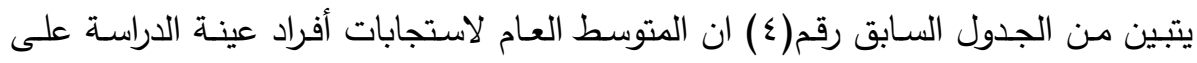
محور متطلبات استخدام الحوسبة السحابية لمعلمى مدارس التعليم الثانوى بمحافظة الفروانية،

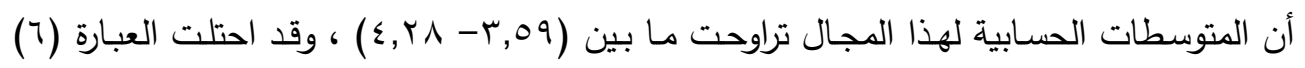
والتي تتص على: عقد دورات تدريبية للمعلمين لتصميم الاختبارات وتصحيحها باستخدام الحوسبة ترابة

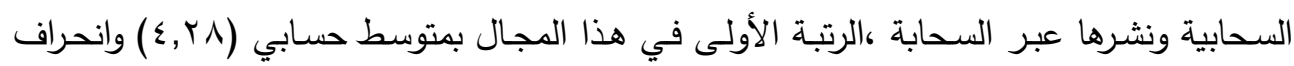

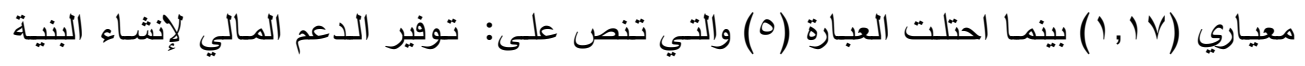

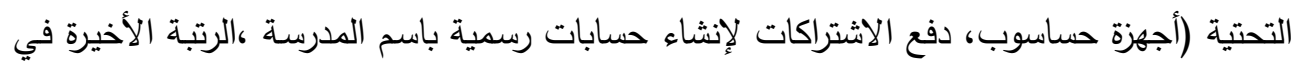




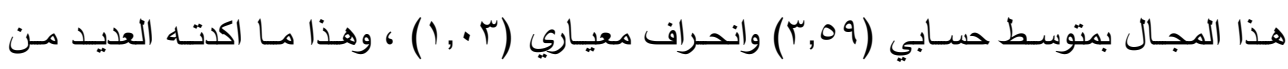

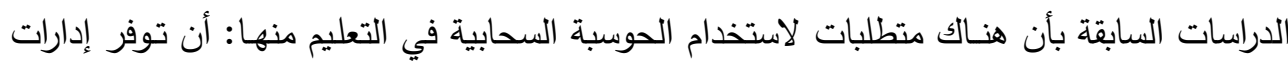

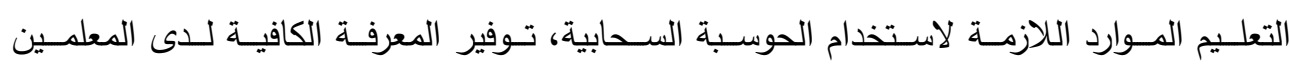

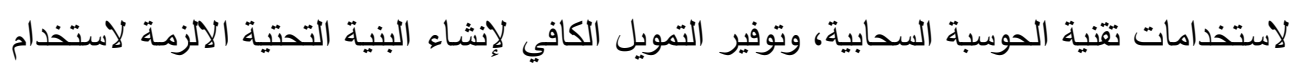
الحوسبة السحابية. ايضا من متطلبـات استخدام الحوسبة تخصص للمنظمـات التعليميـة السحابية في التعليم منها: استئجار بنيـة تحتيـة متكاملة على مستوى وطني، توفير منصات تعليمية خاصـة

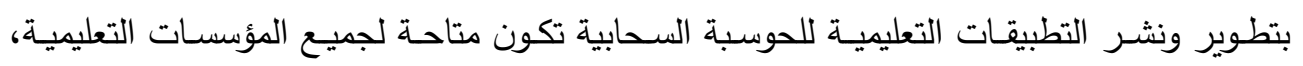
واستخدام سحب مجتمعية تحت مظلـة وزارة التعليم لخدمة للأغراض التعليميـة والبحثيـة، بالإضـافة إلى تدريب الكادر التعليمي على توظيف خدمات الحوسبة السـابية في التعليم، أهميـة امتلاك

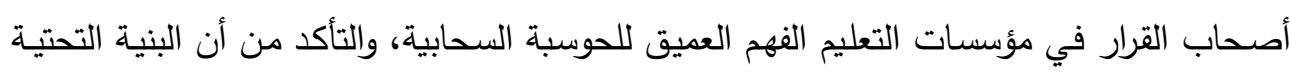
القائمة للمؤسسة تكمل الخدمات القائمة على السحابة. السؤال الرابع:ما التصور المقترح لتحقيق فاعلية استخدام تطبيقات الحوسبة السحابية فى التى

تطوير أداء معلمى المرحلة الثانوية بمحافظة الفروانية؟ فى ضوء ما توصل اليه البحث نستعرض التصور المقترح من خلال المحاور الاتية:

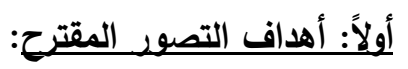
يهدف التصسور المقترح الى تفعيل خدمات الحوسبة السحابية من خـلال تدريب المعلمين

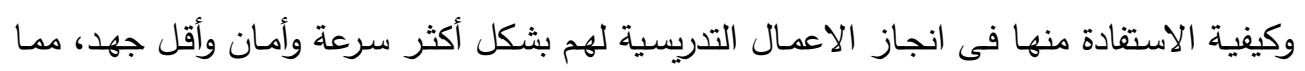
يؤدى الى رفع مستوى جودة العمل والأداء. ثانيًا: المنطلقات الرئيسية للتصور المقترح: ينطلق التصور المقترح من مرتكزان رئيسان: (أ) نتائج الاراسات السابقة: والتى توصلت الى عدة نتائج منها:

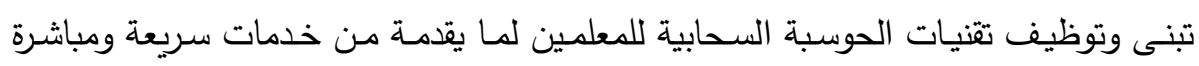
وبجودة عالية، ان خدمات جوجل درايف Googl Drive من ابرز تطبيقات الحوسبة السحابية

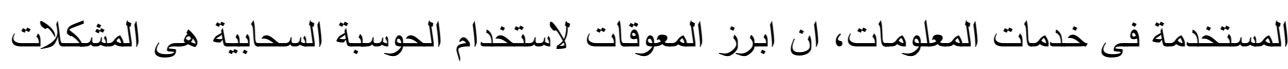

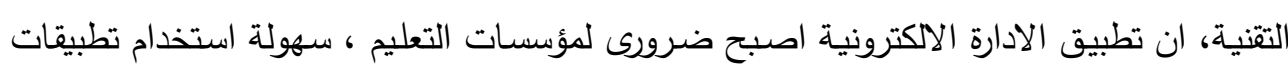
الحوسبة السحابية من الطلاب والمعلمين ومساهتها فى تكوين وجهة نظر ايجابية تؤدى الىى زيادة الدافعية نحو التعلم والعمل التعاوني. (ب) نتائج الاراسة الميدانية: 
فقد جاءت أبرز نتائج الدراسة الميدانية تبعًا لمحاورها كالأتى:

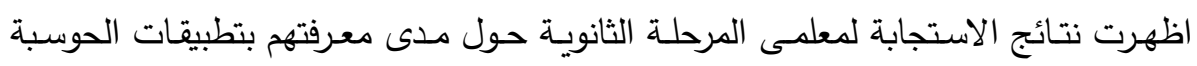

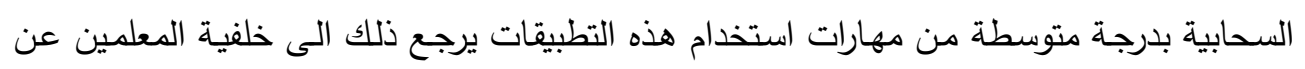

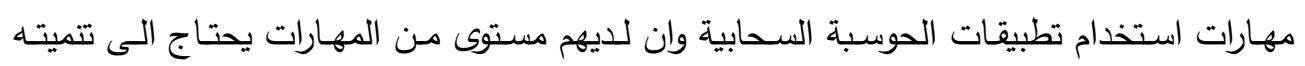
بطريقة تتناسب مع قدراتهم العملية، لذا من الضروري توعية المعلمين والطلبة حول أهمية استخدام

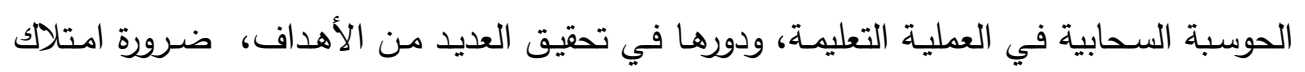

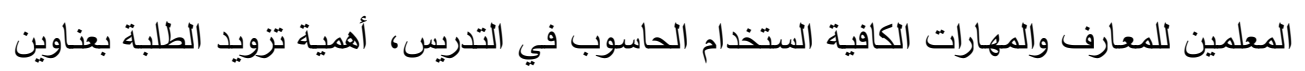

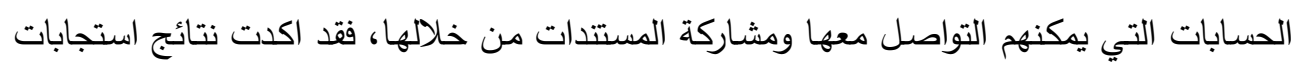
عينة البحث على وجود معوقات لاستخدام الحوسبة السحابية تحد من فاعليتها. ثالثاً: مبرلات التصور المقترح:

يأتى التصور انطلاقًا من الحاجة لتطوير الاداء لمعلمى المرحلة الثانويـة بمدارس المرحلة

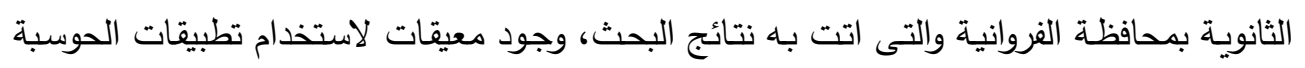

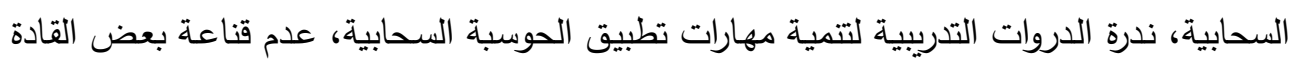

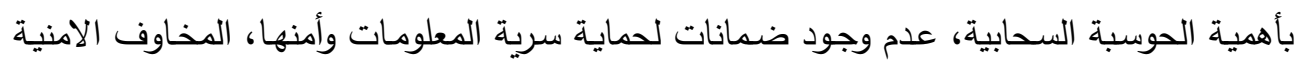
من انتهاك حقوق الملكية الفكرية ، التخوف من مشكلات انقطاع الاتصال بالانترنت.

رليعًا: آلية تنفيذ التصور المقترح:

التتسيق مـع الجهات المختصـة لتتفيذ برامج تطوير مهني تقني فى مجال توظيف الحوسبة السحابية موجه لمعلمى المرحلة الثانوية، تحديد واعتماد مجموعة من التطبيقات الحوسبة السحابية لتفعيلها بين المعلمين فى الددارس، توفير البنية التحتية اللازمة لها، استثمار الكفاءات المتوفرة فى مئي

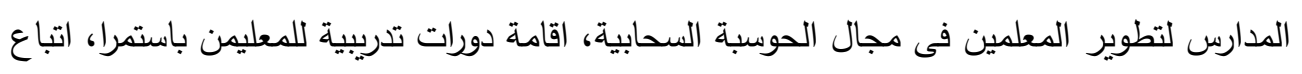

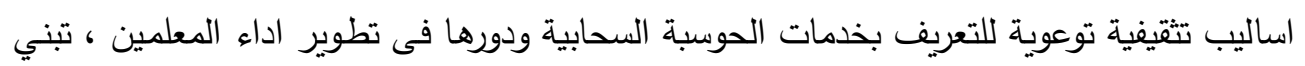
سياسات التشجيع والتحفيز للمعلمين. خامسًا: متطلبات التصور المقترح: بناء على نتائج الدراسة يمكن حصر المتطلبات فيما يلي: تبني برامج تثقيفية لزيادة الوعى باهمية اشستخدام الحوسبة السحابية للمعلمين، تتفيذ برامج تطوير مهني تقنى تتضمن دورات تدريبية فى مجال الحوسبة السحابية، زيادة المخصصات المالية

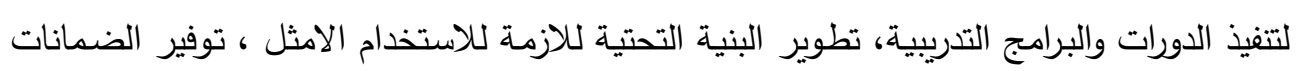


لحماية سرية وامن المعلومات، تطوير الانظمة الادارية الى تدعم التعاملات الالكترونية من خلال الحوسبة السحابية، ايجاد سياسات وقوانين تتيح التعامل بالحوسبة السحابية كوسيلة ادارية رسمية.

$$
\text { توصيات البحث }
$$$$
\text { من خلال النتائج التى تم التوصل اليها فإن الباحث يوصى بالآتي: }
$$

1- توجيه اهتمام القائمين على انتاج البرامج التدريبية الى تصميم برامج تدريبية قائمة على بعض بلى لتصن

$$
\text { تطبيقات الحوسبة السحابية. }
$$

ץ-العمل على توعية معلمى المرحلة الثانوية بضرورة استخدام تطبيقات الحوسبة السحابية لما لها

$$
\text { من مميزات متعددة. }
$$

ب-إقامة دورات متخصصة لاكساب معلمي المرحلة الثانوية مهارات أساسية لاستخدام تطبيقات

$$
\text { الحوسبة السحابية. }
$$

ـ - تثـجيع المعلمين على المشـاركة بندوات علميـة وتكنولوجية وتقديم الأبحاث للتطوير مـن

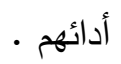

0- أهمية توفير إجراءات الأمان للحسابات المتعلقة باستخدام تطبيقات الحوسبة السحابية.

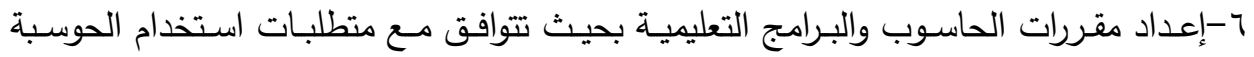

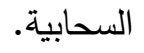

V-التأكيد على أهمية توفير البنية التحتية الالزمة الستخدام تطبيقات الحوسبة السحابية في العملية

$$
\text { التعليمية على وجه العموم، وفى تدريس المقررات المنهجية على وجة الخصوص. }
$$$$
\text { مقترحات البحث }
$$

يقترح الباحث اجراء دراسـات مستقبلية تساهم فى وضـع حلول ومعالجات عملية الارتقاء

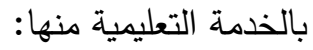

ا - إجراء دراسـات وبحوث حول أثر الحوسبة السحابية على التحصيل وبقاء أثر التعلم لدى

$$
\text { الطلاب في المقررات الدراسية المختلفة. }
$$

ץ- إجراء دراسات وبحوث حول دور الحوسبة السحابية في تتمية مهارت التعلم التشاركي لدى

$$
\text { طالب مقرر طرق تدريس الحاسوب . }
$$

r- إجراء دراسات وبحوث حول الحوسبة السحابية مع عينات أخرى تختلف عن عينة الدراسة

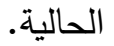

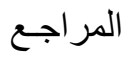




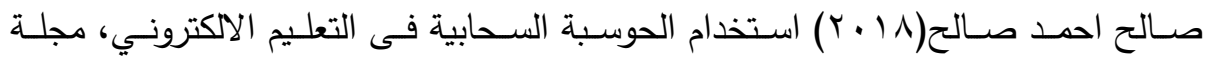

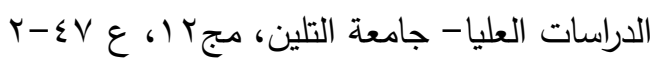

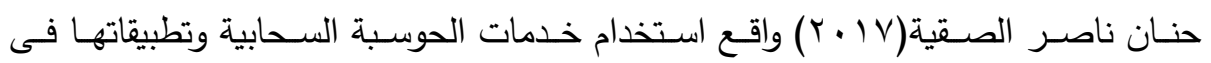

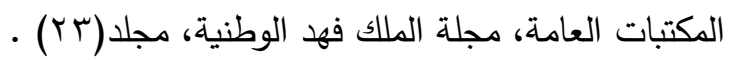

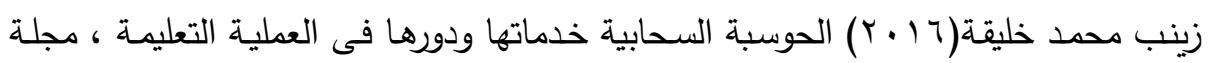
دراسات فى التعليم الجامعى، عدد( (ب).

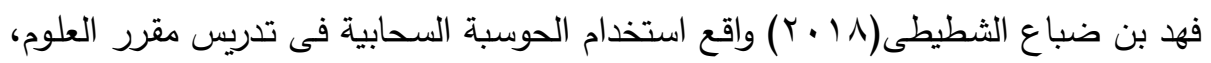

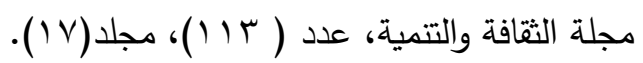

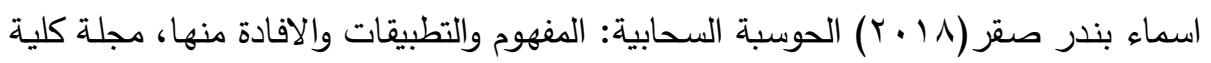
الاداب، جامعة سوهاج، عدد( إ) )، مجلد (Y).

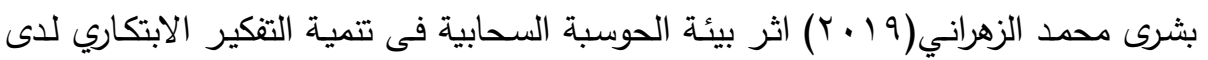
طالبات الصف الثالث الثانوي بالطائف، مجلة كلية التربية، كلية التربية، جامعة اسيوط.

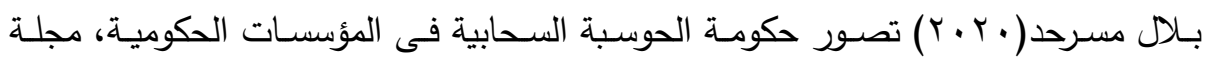

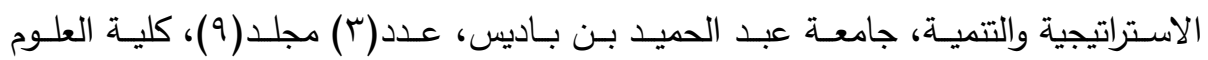
الاقتصادية.

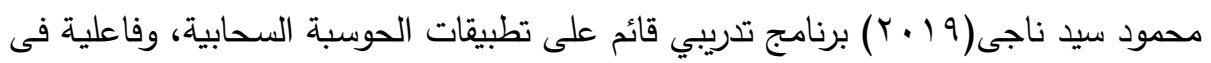

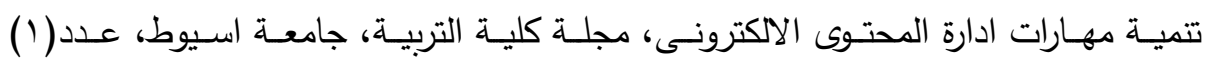

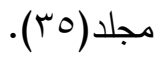

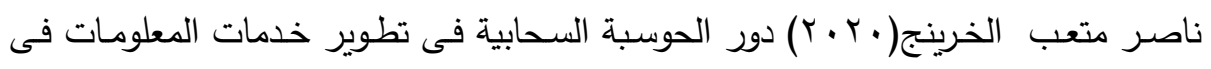
المكتبات الاكاديمية، دراسة مقارنة، المجلة العلمية للمكتبات والوثائق المعلومات، مجلد (؟) ، عدد(ع) كلية الأداب، جامعة القاهرة.

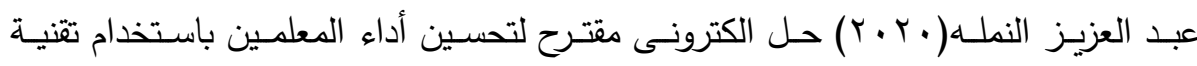

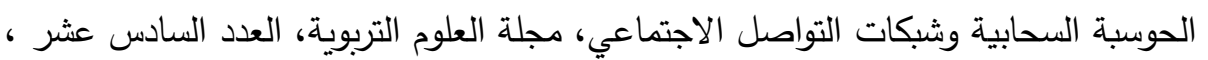
السعودية.

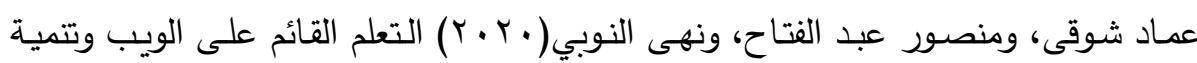

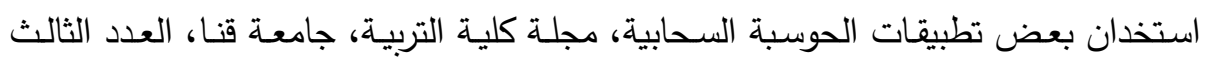

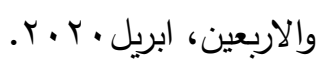


ملمان عبدالعزيز المطوع (9 ( ب) اتجاهات معلمي الحاسب الآلي نحو تطبيقات الحوسبة

السحابية وحاجاتهم التدريبية اللازمة الستخدامها، رسالة ماجستير غير منشورة، كلية التربية،

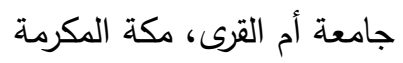

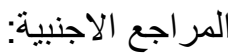

- Kaur, A.(2017). Cloud computing in education : Usingcloudcomputing for education, itpg8.550 cloudbaseditsolutionsresearch report, Eastern Institute Of Technology, p.5. 14-

- Kulkarni P, Khanai R, Bindagi G. (2016). Security Frameworks For MobileCloudComputing: A Survey, International Conference on Electrical, Electronics, and Optimization Techniques (ICEEOT), p.2507.

- Masud, Md. A. H. and Huang, X. (2012). "An E-Learning System Architecture based on Cloud Computing". World Academy of Science, Engineering and Technology, Melbourne, Australia

- Bora, U., Ahmed, M. (2013). E-Learning using Cloud Computing, International Journal of Science and Modern Engineering (IJISME), $1(2), 9-12$ 